\title{
Landmine Policy in the Near-Term: A Framework for Technology Analysis and Action
}

\author{
David Eimerl
}

August 1997

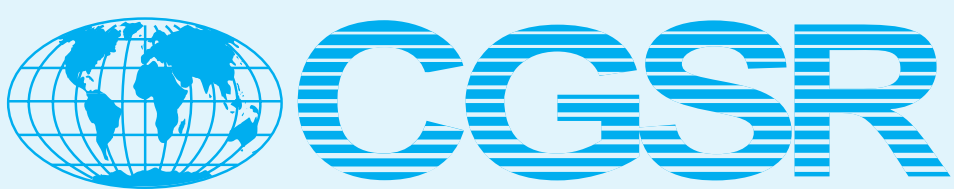

Center for Global Security Research 
The Center for Global Security Research (CGSR) was established at Lawrence Livermore National Laboratory (LLNL), Livermore, CA, in 1996. CGSR helps to enhance global security through analyzing and understanding the factors that could lead to reducing the threat associated with weapons of mass destruction and other advanced weapon types. Primary emphasis is on bridging the gap between the technology and policy communities by evaluating how technology can enhance the international security framework. Broad international participation is encouraged, and term assignments to the CGSR are available. CGSR develops its research programs through "calls for proposals." Successful applicants will be given a term assignment to the CGSR for the period required to perform the work.

Specific objectives of the CGSR are:

- To provide the United States and international agencies with detailed analysis of the technical options associated with effective management, control, and reduction of the threat arising from weapons of mass destruction and other advanced weapon types.

- To provide an integrating mechanism for the multidisciplinary and diverse arms control and nonproliferation study activities at LLNL.

- To provide an outreach to campuses and other academic institutions, industry, government, and international organizations.

- To provide a forum for training/discussion of international security issues among diverse communities.

For information about CGSR and "calls for proposals," please contact the CGSR Director at:

Center for Global Security Research

Lawrence Livermore National Laboratory

P.O. Box 808 , L-189

Livermore, California 94551

USA

Phone: (510) 422-6141

FAX: (510) 422-5252

Internet home page:

http:/ / www.llnl.gov/nai/cgsr.html

The Center for Nonproliferation Studies (CNS) at the Monterey Institute of International Studies addresses the international proliferation of nuclear, missile, biological, chemical, and advanced conventional weapons technologies. Established in 1989, the CNS provides research tools, analysis, training, and education on nonproliferation issues to scholars and policymakers around the world. The Center currently has a staff of 35 full-time and more than 40 part-time personnel, making it the largest nongovernmental program in the United States devoted exclusively to research and training on nonproliferation issues.

The Chemical and Biological Weapons (CBW) Nonproliferation Project at the CNS monitors the proliferation of chemical and biological weapons and develops strategies for halting and reversing their spread. The project emphasizes "demand-side" approaches to CBW nonproliferation: efforts, such as global arms control regimes and regional confidence-building measures, to change the incentive structure of proliferators so that they no longer seek these weapons. Current research activities cover three areas: (1) monitoring compliance with the Biological Weapons Convention; (2) overcoming obstacles to chemical disarmament in Russia; and (3) assessing motivations for acquisition of CBW by states and terrorist groups.

For information about the CBW Nonproliferation Project and the CNS, please contact:

Chemical and Biological Weapons Nonproliferation Project

Center for Nonproliferation Studies

Monterey Institute of International Studies

425 Van Buren Street

Monterey, California 93940

USA

Phone: (408) 647-4154

FAX: (408) 647-3519

e-mail: cns@miis.edu

Internet home page: http://cns.miis.edu 


\title{
Landmine Policy in the Near-Term:
}

\section{A Framework for Technology Analysis and Action}

\author{
David Eimerl \\ Center for Global Security Research \\ Lawrence Livermore National Laboratory \\ P.O. Box 808, Livermore California 94550
}

13 August 1997 


\section{DISCLAIMER}

This document was prepared as an account of work sponsored by an agency of the United States Government. Neither the United States Government nor the University of California nor any of their employees, makes any warranty, express or implied, or assumes any legal liability or responsibility for the accuracy, completeness, or usefulness of any information, apparatus, product, or process disclosed, or represents that its use would not infringe privately owned rights. Reference herein to any specific commercial product, process, or service by trade name, trademark, manufacturer, or otherwise, does not necessarily constitute or imply its endorsement, recommendation, or favoring by the United States Government or the University of California. The views and opinions of authors expressed herein do not necessarily state or reflect those of the United States Government or the University of California, and shall not be used for advertising or product endorsement purposes.

This report has been reproduced directly from the best available copy.

Available to DOE and DOE contractors from the Office of Scientific and Technical Information P.O. Box 62, Oak Ridge, TN 37831

Prices available from (423) 576-8401

Available to the public from the National Technical Information Service

U.S. Department of Commerce

5285 Port Royal Rd.,

Springfield, VA 22161

Work performed under the auspices of the U.S. Department of Energy by Lawrence Livermore National Laboratory under Contract W-7405-ENG-48. 


\section{Table of Contents}

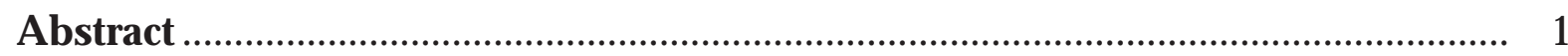

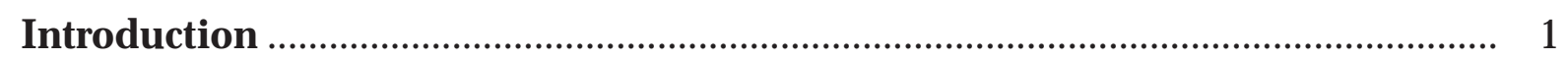

The Landmine Situation..................................................................................... 3

The Need for Land Certification........................................................................... 4

Certification Involves Vast Land Areas ................................................................... 4

Can We Afford Land Certification? .................................................................... 6

Sustainable Demining ........................................................................................ 10

The Nature of the Mined Areas: The Beginnings of a Solution............................. 11

What Constitutes a Mine? ………………………............................................ 12

Technology for Removing Landmines .............................................................. 13

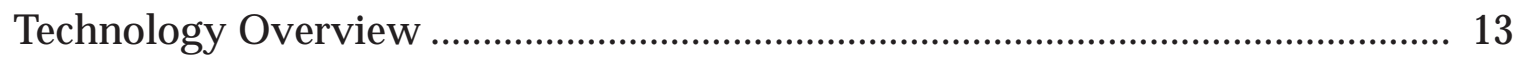

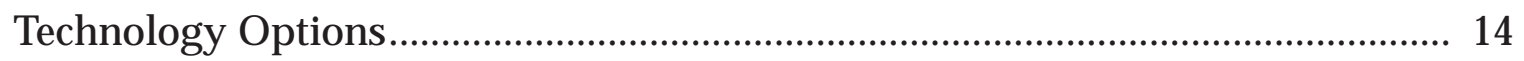

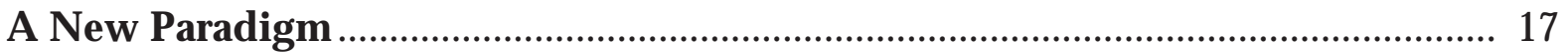

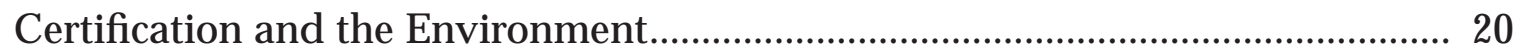

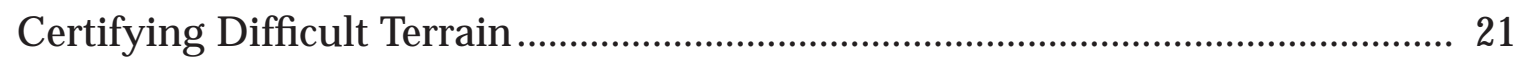

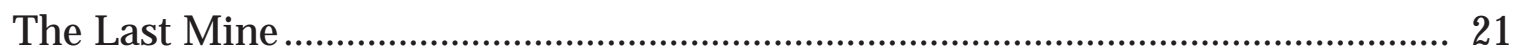

Construct for Worldwide Action......................................................................... 22

Prioritizing Land for Certification: The Reconstruction Plan .............................. 22

Scale and Nature of Worldwide Effort to Eradicate Landmines .......................... 24

World Demining Organization? ......................................................................... 26

Proliferation and Growth Abatement ................................................................. 27

Future Military Use of Landmines.................................................................. 28

Conclusions: Landmine Action Policy Implications ……………………….......... 29

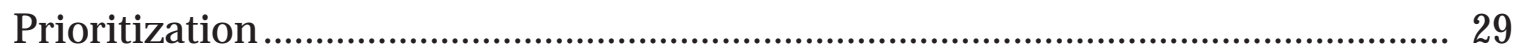

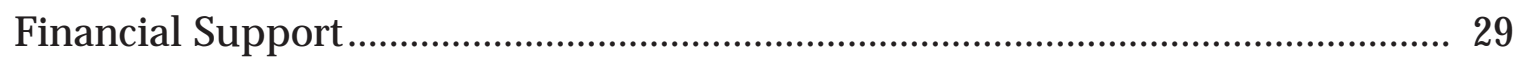

Technology Development ............................................................................... 30

Maps and Other Supporting Data.................................................................... 30

Other Recommendations ..................................................................................... 31

Appendix A. Conference on Techology Needs for Humanitarian Demining...... 33

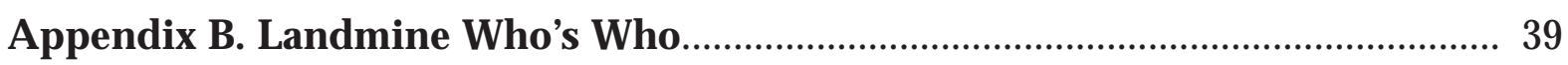

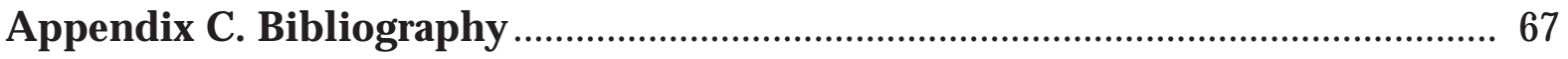




\section{List of Illustrations}

Figure

1 Landmine Situation Overview ...................................................................... 1

2 Traditional Clearing Operations Are Slow and Expensive ............................. 6

3 Labor Rate, Coverage Rate, and Affordability ........................................... 15

4 Capital Amortization Rate, Coverage Rate, and Affordability ....................... 15

\section{Table}

1 Landmine Injuries Are an Epidemic .............................................................. 2

2 Land Use and Economy Statistics by Country ............................................ 8 


\title{
Landmine Policy in the Near-Term:
}

\section{A Framework for Technology Analysis and Action}

\author{
David Eimerl \\ Center for Global Security Research \\ Lawrence Livermore National Laboratory \\ P.O. Box 808, Livermore California 94550
}

13 August 1997

\begin{abstract}
Any effective solution to the problem of leftover landmines and other post-conflict unexploded ordnance (UXO) must take into account the real capabilities of demining technologies and the availability of sufficient resources to carry out demining operations. Economic and operational factors must be included in analyses of humanitarian demining. These factors will provide a framework for using currently available resources and technologies to complete this task in a time frame that is both practical and useful. Since it is likely that reliable advanced technologies for demining are still several years away, this construct applies to the intervening period. It may also provide a framework for utilizing advanced technologies as they become available. This study is an economic system model for demining operations carried out by the developed nations that clarifies the role and impact of technology on the economic performance and viability of these operations. It also provides a quantitative guide to assess the performance penalties arising from gaps in current technology, as well as the potential advantages and desirable features of new technologies that will significantly affect the international community's ability to address this problem. Implications for current and near-term landmine and landmine technology policies are drawn.
\end{abstract}

\section{Introduction}

Landmines left over from military conflicts continue to kill and injure innocent civilians long after their military function has ceased. These landmines are killing thousands of people a year, mostly farmers and children. The injury rate has reached epidemic proportions-the scale of the tragedy is wellillustrated by the representative data shown in Table 1. In this paper, we explore the nature of the landmine problem and the role of technology in its solution. This type of analysis can serve as a guide for advanced technology as well as provide specific parameters that advanced technologies must meet in order to be effective.
The landmine problem can be divided into three areas: injuries and their prevention, removing currently emplaced landmines, and preventing the problem from recurring. This is illustrated in Figure 1. The solution in each of these areas will be multifaceted and complex, and it will involve international action. A significant element of the solution is that it must be politically acceptable to all those affected by it, from families living with the risk or reality of injury, to governments at the local and national levels. One expects that solutions to all aspects of the problem will be facilitated, or even created, by advanced technologies, albeit of widely different character. But the problem of removing mines (and that of recovering the use of 


\section{Landmine Policy in the Near-Term}

Table 1. Landmine injuries are an epidemic.*

\begin{tabular}{|c|c|c|c|c|c|}
\hline Country & Population† & $\begin{array}{l}\text { Number of } \\
\text { mines } \\
\text { (millions) }\end{array}$ & $\begin{array}{l}\text { Mines per } \\
\text { inhabitant }\end{array}$ & $\begin{array}{c}\text { Total } \\
\text { number of } \\
\text { amputees }^{\star \star}\end{array}$ & $\begin{array}{c}\text { Amputees } \\
\text { per } \\
\text { inhabitant }\end{array}$ \\
\hline \multicolumn{6}{|l|}{ Africa } \\
\hline Angola & 10.2 & 15 & 1.47 & 30,000 & 1 per 334 \\
\hline Eritrea & 3.4 & 1 & 0.29 & 2,000 & 1 per 1,700 \\
\hline Ethopia & 53.3 & 0.5 & 0.01 & 8,000 & 1 per 6,663 \\
\hline Mozambique & 16.9 & 3 & 0.17 & 7,000 & 1 per 2,414 \\
\hline Somalia & 8.54 & 1 & 0.12 & $\mathrm{~N} / \mathrm{A}$ & $\mathrm{N} / \mathrm{A}$ \\
\hline Sudan & 27.25 & 1 & 0.04 & 5,000 & 1 per 5,450 \\
\hline \multicolumn{6}{|l|}{ Asia } \\
\hline Afganistan & 22.1 & 10 & 0.45 & 35,000 & 1 per 631 \\
\hline Cambodia & 9.6 & $8-10$ & $0.83-1.040$ & 25,000 & 1 per 384 \\
\hline Myanmar & 44.7 & unknown & $\mathrm{N} / \mathrm{A}$ & 6,000 & 1 per 7,450 \\
\hline Viet Nam & 70.9 & 3.5 & 0.05 & 60,000 & 1 per 1,182 \\
\hline \multicolumn{6}{|l|}{ Europe } \\
\hline Hertzegovina & 4.4 & 6 & 1.36 & $\mathrm{~N} / \mathrm{A}$ & $\mathrm{N} / \mathrm{A}$ \\
\hline Croatia & 4.8 & 6 & 1.25 & $\mathrm{~N} / \mathrm{A}$ & $\mathrm{N} / \mathrm{A}$ \\
\hline \multicolumn{6}{|l|}{ Middle East } \\
\hline Iraq & 19.75 & 10 & 0.51 & 20,000 & 1 per 987 \\
\hline
\end{tabular}

* Source: UN Department of Humanitarian Affairs Landmine Database (August 1996)

$\dagger$ Source: World Bank Atlas-1995, except for pop. of Eritrea, which is from UNICEF.

${ }^{* *}$ Where figures are difficult to get, the number of estimated amputees reflects a conservative estimate.

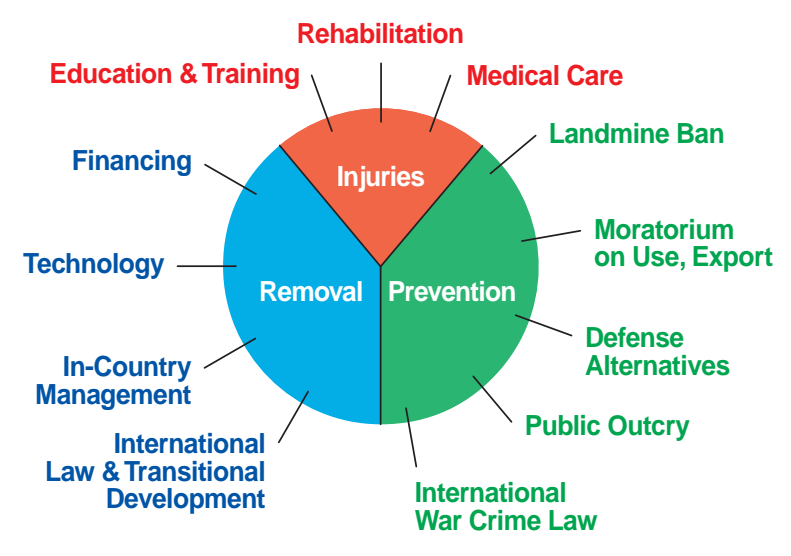

$\mathrm{N} / 1187-01$

Figure 1. Landmine situation overview.

mined lands for peaceful purposes) stands out as by far the most challenging. Indeed, it may well be the first and perhaps one of the greatest humanitarian concerns of the 21st century, one that will challenge scientists, engineers, and politicians for many years to come.
The core of the problem is that while landmines are small, inexpensive, and easily laid, they are difficult to detect and expensive to recover. It is well-known to commercial technology companies that products can be built either to a cost target or to a performance specification, but if both cost and performance are constrained, any solution may be precluded. So it is with mine clearance. Traditional methods of remediating minefields are much too slow, and will require an infusion of financial support well beyond the resources usually made available for humanitarian concerns. Advanced methods that meet the performance requirements appear to be too expensive; yet affordable methods evidently do not meet these requirements. To bring the challenge to new technology as far as possible within range of current science and engineering practice, it is necessary first to frame the problem accurately, then to create a system model for the solution, and finally to analyze the requirements for new 


\section{A Framework for Technology Analysis and Action $\mid \mathbf{3}$}

technology in the context of that system solution. The system model and its analysis then serves as a guide for developers of technology, financial underwriters, foreign policy experts, and local governments to frame a course of action for dealing with the problem.

It is the aim of this paper to pursue this program, and to provide a construct for a workable solution to the landmine problem. If it is successful, the measure of its success will be the extent to which the ideas developed here will be accepted or even adopted by those who frame international policy and those responsible for technology development.

\section{The Landmine Situation}

Landmines as a humanitarian concern were first brought to light as an international issue by the International Committee of the Red Cross (the ICRC) in the early 1990s. The ICRC found that landmine injuries were occurring at the rate of 25,000 to 30,000 per year, and that the reported injury rate was increasing dramatically. The most common victims were returning displaced refugees or families growing crops for food, and the injuries occurred almost exclusively in regions of the world where the ICRC is the main agency for providing care and treatment of these victims. Humanitarian relief efforts are barely adequate to provide care and treatment. Noting that the injuries occurred mainly in unattended, post-conflict minefields and that mines generally do not discriminate between soldiers and non-combatants, the ICRC pointed out that such minefields are in contravention of international law, and mounted a campaign to publicize this situation. As a result of their efforts, many governments have agreed to a temporary moratorium on the use of mines, and a landmine ban has been proposed. Modifications of international law and the conduct of war in order to stem the emplacement of indiscriminate landmines are under active consideration. Programs to clear postconflict minefields are growing in Western Europe and North America.

While the injury rate is well-documented, the location and nature of the post-conflict minefields themselves are poorly known, in general. Although current military practice requires that minefields be thoroughly mapped to facilitate post-conflict clearing, such documentation is virtually nonexistent for many minefields, and the lack of such documentation is a significant impediment to providing relief. Information on unmapped minefields is primarily circumstantial. The primary sources of information are the history of recent conflicts, the combatant's statements, civilian reports, and any physical evidence of mines. Economic measures are of limited use in estimating the number of undocumented emplaced mines. Total world production in recent times is approximately 300 million mines. It seems likely that only a small fraction of these are actually emplaced, with the remainder in storage.

Assertions of the number of mines suspected to represent the hazard may well be inflated, for several reasons. Mines have a tremendous psychological impact. A farm worker seeing a mine detonate nearby will pause and proceed with great caution; a person seeing another person injured may well be virtually paralyzed. Sometimes an injured person may take days to die in a remote location far from medical care. The chronic stress of living with the risk of injury makes mines and booby-traps indiscriminate weapons of terror. A terrorist can paralyze a community by the simple tactic of claiming that a large area is mined, yet having emplaced only a few mines in strategic locations near population centers or in tilled land. The victimized community does not know how many mines there are, but fears that the entire area may indeed be mined, and is overwhelmed by the problem of clearing the area. The number of mines would be estimated as if the whole area was mined. Also, in calling for aid, community members 
may be inclined to exaggerate the problem in the belief that the more mines they claim, the more likely they are to receive assistance. Problem inflation may also have been practiced by observers with humanitarian motives, who are incensed by the extent of the tragedy, and who desire to shock the international community into action, or at least to avoid underestimating the problem. These factors all provide inflationary pressure on the estimates of suspected mines.

Some studies have suggested that there may be as many as 120 million undocumented mines in the ground. It should be remembered that these mines are unknown by definition and that there is, in fact, no reliable way to estimate their number. Given the circumstantial evidence used to estimate them, the inflationary pressures on reporting them, and the actual rate of discovery during demining operations, it is possible that the number of mines is considerably smaller, perhaps even as low as 10 million mines. (This figure refers to mines rather than all forms of UXO.)

\section{The Need for Land Certification}

Thus, the landmine situation is one of considerable uncertainty and possible exaggeration in regard to the nature and extent of the mined areas. Yet the injury rate is probably at least as great as that reported. However, it is important to distinguish between the technical parameters of the landmine situation and the problem that they represent. In fact, estimates of the total number of mines are not especially relevant. The enduring problem is the dislocation of communities that are denied the use of their land, and are at the same time burdened with the tragedy of physical injury. It is enough that a community believes that a problem exists in order for it to leave large areas of land unused, dislocating the life of that community. Once the perception of a problem has been created, perhaps by the occurrence of an injury, the safety of the land has been forever compro- mised. The community will avoid the area as much as is feasible, regardless of how many mines are actually present. Such perceptions can be created by malice, mischief, or accident when there are actually no mines present, or an existing risk can be exaggerated for effect. There is only a weak deterministic relation between the actual presence of mines and the perception of risk. Once challenged, land will only come back into use if it is certified free of mines to a level of safety sufficient to persuade people to use it again. For example, there are fields in northern Europe containing live munitions from World War I and World War II. It occasionally happens that one of them is dug up. When that occurs, a farmer is very likely to be injured or killed. But this does not deter the local community from using and farming the land. In Cambodia, villagers take considerably higher risks of injury when they work in the rice fields. Each local area has its own standard of acceptable risk. To bring the land back into use, a credible method of land certification is needed.

Thus the technical problem created by landmines is the exclusion of land from use, and the solution is land reclamation by certification. It is in the context of land certification that the technical parameters of the landmine problem must be evaluated.

\section{Certification Involves Vast Land Areas}

Certification means carrying out actions that the local community believes will determine that the risk is within acceptable limits. It does not necessarily mean removing all mines. As a practical matter, certification means that all remaining ordnance is sealed off from accidental human contact, and that the number of injuries is reduced to a level that the local population feels is adequately low. Nonetheless, it is essential that the methods used be thoroughly credible, accurate, and reliable. One method of certification is nondestructive search and destroy. Another method is to bury the remaining 


\section{A Framework for Technology Analysis and Action $\mid \mathbf{5}$}

mines under concrete structures as part of normal economic development. An example of this is found in England, where about 3200 unexploded bombs from World War II remain buried under the modern buildings of London, well-sealed and protected from inadvertent contact by unwary individuals. This is one option for effective mine action. Although such environmentally minimally destructive methods are not the only approaches to land certification, for obvious reasons, methods that disturb the land, move earth, destroy vegetation, or demolish buildings have been deemed less attractive and have received less attention.

The area to be certified is difficult to estimate on purely technical or physical grounds because the number and location of deployed mines is known primarily through incomplete circumstantial and historical evidence. However, the land to be certified is not necessarily the same as the land that is actually mined. Rather, it is that land where mines are thought to exist or to pose a potential problem. The certification task deals with the potential or perceived problem, not the actual physical presence of mines. One way to estimate the compromised area is to take the total number of mines, 100 million, and divide it by average mine density, which the UN estimates as 15 mines per hectare. This procedure estimates the total compromised land as 7 million hectares. Even taking into account the considerable uncertainty in this method, the affected area is comparable to that of a small country. Certification requires this land to be surveyed, searched, and cleared with a resolution of from a few inches $(10 \mathrm{~cm})$ up to a depth of as much as $100 \mathrm{~cm}$ to be certain that all mines are located and appropriately destroyed. The procedure must have a confidence level high enough that no mine can slip through undetected. Also, it must be effective in any terrain where certification is required. This may include areas of forest and woodland, crop fields, desert, beach, sand, marshes, swamps, rice fields, village buildings, etc. The magnitude of the task is vast, at least by this measure.

However, the near-term goal is not to certify all the compromised land, but to certify enough land to enable the local community to form a stable and growing economic unit. One method of evaluating the compromised land is to conduct surveys of land use in areas where mines or the threat of mines are known to cause significant dislocation in the life of the local community. Data-on land in current use, land that the local community does not use because it has been compromised, land not in current use that it desires to put to use, the population of the local community, and the regional average for the number of people each hectare of land can support-is relevant. Such data can be used to estimate how much land needs to be certified and what level of mine action will meet the local need. A useful criterion for mine action is that each local community should have sufficient land to support itself at roughly the same quality of life (or standard of living) as the average for the greater regional population. Merely arranging for the availability of sufficient land of adequate production capability will probably be insufficient as a stand-alone criterion. Local cultural, historical, political, and religious factors will appear in setting priorities on the value of certain lands to the local community. Nonetheless, the general principle of arranging for the quality of life in the local community to be commensurate with that in the greater area (which ideally would include areas that have not been mined) can be used to estimate the scope of the near-term problem. Long-term, of course, the ideal would be a world entirely free of landmines.

The current method of minefield survey is a combination of traditional clearing methods and the use of dogs trained to sniff out landmines. Advanced technology, such as airborne multispectral imaging, is currently being test by the United States NATO forces in Bosnia. 
The current method of mine removal for open terrain in suitable ground is to probe the ground manually with a long knife or rod, and to clear light vegetation with machinery. This is illustrated in Figure 2. The manual search rate is slow (about $5 \mathrm{~m}^{2}$ /hr per deminer), and the cost is approximately $\$ 0.5 / \mathrm{m}^{2}$. Mine clearance in other terrain (such as the canopied regions of Cambodia) is considerably more expensive and proceeds much more slowly. At this rate, searching and clearing all the compromised land will cost at least $\$ 50$ billion, comparable to or more than the GNP of many of the countries that have mines. This cost estimate dwarfs the total investment of funds for demining worldwide, which is less than $\$ 100$ million.

Another estimate of the scale of the problem comes from the manpower requirements. If the 7 million hectares of compromised land are to be covered over a 25-year period, the hourly rate would be about $150 \mathrm{ha} / \mathrm{hr}$, which, at the current manual probing rate, would require a standing demining force of 300,000 deminers. For comparison, the current manpower level of the entire U.S. army is 495,000. The required demining force, by this measure, is on the scale of one of the larger standing armies of the world. The cost of maintaining such a demining force is well beyond available resources.

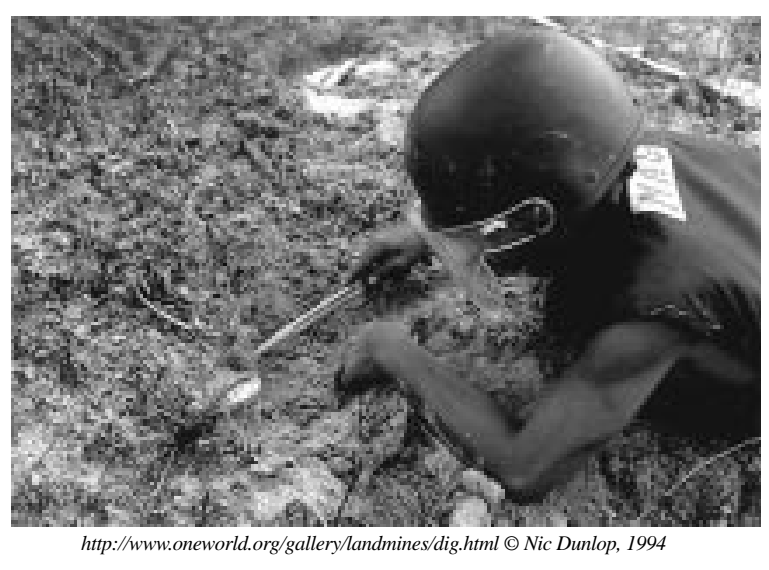
$\mathrm{N} / 1187-02$

Figure 2. Traditional clearing operations are slow and expensive.
Another aspect of the problem concerns the rate of mine emplacement. The compromised area was mostly mined in recent conflicts. If the claimed 100 million mines are assumed to have been laid over the last 20 years, then the average emplacement rate over that period is about 2500 mines per workday hour, or about 160 ha/hr. Clearing and recertification must exceed that rate to have a net effect on the problem.

This calculation clearly illustrates that using the published data to make coarse estimates of cost and manpower makes the problem seem insurmountable. Yet this calculation may well be misleading. The assumption that all areas in the tagged minefields are equally likely to contain mines is certainly false, and the accuracy of the data used to make this simple estimate renders the answer highly questionable. However, even if these estimates are off by an order of magnitude, it is clear that the scale of the land certification problem is potentially vast, involving large tracts of land. Moreover, if all of this area has to be searched as if every square meter is likely to contain a mine, then current methods of mine removal will probably have a disappointingly small effect on injury rates and on land reclamation. Fortunately, it is very likely that even though the compromised area may well be this large, the solution does not require using these painstakingly slow search-and-disposal methods over the entire compromised area. Indeed, it is likely that the problem can be brought under control for a much smaller investment than these estimates imply. We are suggesting in this paper that the task is much more manageable.

\section{Can We Afford Land Certification?}

The benefits of land recertification include integration of the reclaimed land into the economic life of the community and a reduction in the rate of injuries. Each hectare of land that is certified and returned to the community will generate income at a given 


\section{A Framework for Technology Analysis and Action $\mid 7$}

rate depending on its use. Each mine removed reduces the risk of further injury. If the land is returned to the same condition, and for the same use, as it had before being compromised, the local economy benefits at that rate. The immediate question is whether the local economy can afford to have lands certified. Let us look very broadly at the economics of land certification-the income generating potential of the land, versus the cost of certifying it.

For agricultural land in primarily agricultural communities, the income-generating potential of land is measured by the national product per hectare in the agricultural sector. Relevant economic data on many countries is presented in Table 2. From this table, we see that for a poor country whose economy is primarily agricultural, the income per hectare may be only a few hundred dollars per year. Assuming that the community could be taxed even at $5 \%$ for 20 years to pay for land certification, that would only generate perhaps one or two thousand dollars per hectare.

The cost of demining using inexpensive tools is calculated by summing the cost of field labor and organizational support. The field labor cost includes paying for local deminers as well as for expatriate trainers (typically about ten to one). The cost of local labor can reasonably be taken as lying between the national product per worker in the agricultural sector, and the national product per worker in the regional economy. For most moderate and low income countries this estimate gives the range $\$ 1000$ to $\$ 5000$ per annum. When benefits are included, the cost of trainers is typically comparable to the cost per worker in developed nations' economies, or about $\$ 25,000$ to $\$ 75,000$ per annum, depending on function, country of origin, and experience. Organizational support could be provided by a force of about one support worker for every ten trainers, with the addition of significant overhead. Therefore, organizational support is reasonably priced at about half the trainer costs. Thus, a team of 100 deminers, 10 trainers, and one organization person with overhead will cost between $\$ 0.5$ million and $\$ 1.6$ million per year. Equipment and other support functions are an additional expense. For a 2000-hour work year, the total hourly rate per deminer lies between $\$ 2.5$ and $\$ 8 / \mathrm{hr}$. For comparison, the U.N. has suggested that the total hourly cost per deminer is about $\$ 3$.

At a demining rate of $5 \mathrm{~m}^{2} / \mathrm{hr}$ (standard for demining flat, easily penetrable earth with no problematic vegetation), the current cost of demining is between $\$ 5,000$ and $\$ 16,000 /$ ha. For terrain where vegetation, soil type, or stones and rocks slow the work of deminers, the cost can be many times higher.

Even though the caveats of this calculation are evident, it is evident that a great disparity exists between the income and costs associated with demining as a straightforward for-profit investment opportunity. Clearly, returned land cannot generate enough income to pay for the cost of mine removal over all parts of a mined region. While one might hope that a capitalist approach would provide enough resources to solve the problem, this is obviously not the case. Not only is the capitalist or international investment approach unworkable and impractical as a policy, it is also unfairly punitive: none, or almost none, of the financial burden of certification would be borne by those who created the problem; rather, the cost would be borne almost completely by the victims. This is clearly incompatible with a humanitarian worldview.

At the other extreme, we can take the approach that the world community of nations should shoulder the financial burden without regard to national or ideological boundaries. In this approach, the idea that investors should obtain an adequate financial return on investment, in the microeconomic sense, is replaced by a long-range, macroeconomic worldview, where the community of nations acts out of enlightened self-interest for the world as a whole. The World Domestic Product (WDP) is about \$30 trillion, and the world population is about 


\section{Landmine Policy in the Near-Term}

Table 2. Land use and economy statistics by country.*

\begin{tabular}{|c|c|c|c|c|c|c|c|c|c|}
\hline Country & $\mathbf{P}$ & NP & $\mathrm{Ag}$ & Area & AR & PC & MP & FW & Ot \\
\hline Afghanistan & 21.25 & & & 64.75 & 12 & 0 & 46 & 3 & 39 \\
\hline Albania & 3.41 & 1110 & 55 & 2.74 & 21 & 4 & 15 & 38 & 22 \\
\hline Algeria & 28.54 & 3480 & 12 & 238.1 & 3 & 0 & 13 & 2 & 82 \\
\hline Angola & 10.07 & 620 & 15 & 124.7 & 2 & 0 & 23 & $4 \overline{3}$ & 32 \\
\hline Argentina & 34.29 & 7990 & 8 & 273.7 & 9 & 4 & 52 & 22 & 13 \\
\hline Armenia & 3.56 & 2290 & & 2.84 & 17 & 3 & 20 & 0 & 60 \\
\hline Azerbiajan & 7.79 & 1790 & & 8.61 & 18 & 4 & 25 & 0 & 53 \\
\hline Bangladesh & 128.0 & 1040 & 33 & 13.391 & 67 & 2 & 4 & 16 & 11 \\
\hline Belize & 0.2 & 2750 & 30 & 2.28 & 2 & 0 & 2 & 44 & 52 \\
\hline Bosnia/Herzegov & 3.2 & $<1000$ & 9 & 5.12 & 20 & 2 & 25 & 36 & 17 \\
\hline Botswana & 1.39 & 3130 & 5 & 58.54 & 2 & 0 & 75 & 2 & 21 \\
\hline Bulgaria & 8.78 & 3830 & & 11.06 & 34 & 3 & 18 & 35 & 10 \\
\hline Burma & 45.1 & 930 & 65 & 65.77 & 15 & 1 & 1 & 49 & 34 \\
\hline Cambodia & 10.56 & 630 & & 17.65 & 16 & 1 & 3 & 76 & 4 \\
\hline Cameroon & 13.52 & 1200 & 25 & 46.94 & 13 & 2 & 18 & 54 & 13 \\
\hline Chad & 5.59 & 530 & 45 & 125.9 & 2 & 0 & 36 & 11 & 51 \\
\hline Congo & 2.5 & 2820 & 12 & 34.15 & 2 & 0 & 29 & 62 & 7 \\
\hline Croatia & 4.67 & 2640 & & 5.64 & 32 & 20 & 18 & 15 & 15 \\
\hline Ecuador & 10.89 & 3840 & 14 & 27.68 & 6 & 3 & 17 & 51 & 23 \\
\hline Egypt & 62.34 & 2490 & & 99.54 & 3 & 2 & 0 & 0 & 95 \\
\hline El Salvador & 5.87 & 1710 & 24 & 2.07 & 27 & 8 & 29 & 6 & 30 \\
\hline Eritrea & 3.58 & 500 & & 12.13 & 3 & 2 & 40 & 5 & 50 \\
\hline Ethiopia & 55.92 & 380 & 45 & 111.9 & 12 & 1 & 41 & 24 & 22 \\
\hline Falkland Is & 0.002 & $\mathrm{n} / \mathrm{a}$ & $>90$ & 1.22 & 0 & 0 & 99 & 0 & 1 \\
\hline France & 58.11 & 18670 & 4 & 54.56 & 32 & 2 & 23 & 27 & 16 \\
\hline Germany & 81.34 & 16580 & 1 & 34.95 & 34 & 1 & 16 & 30 & 19 \\
\hline India & 936.6 & 1360 & 34 & 297.31 & 55 & 1 & 4 & 23 & 17 \\
\hline Korea, N & 23.48 & 920 & 25 & 12.04 & 18 & 1 & 0 & 74 & 7 \\
\hline Korea, S & 45.55 & 11270 & 8 & 9.82 & 21 & 1 & 1 & 67 & 10 \\
\hline Kuwait & 1.87 & 16900 & & 1.78 & 0 & 0 & 8 & 0 & 92 \\
\hline Laos & 4.84 & 850 & 50 & 23.08 & 4 & 0 & 3 & 58 & 35 \\
\hline Libya & 5.28 & 6510 & 5 & 175.95 & 2 & 0 & 8 & 0 & 90 \\
\hline Morocco & 29.17 & 3060 & 15 & 44.63 & 18 & 12 & 28 & 12 & 41 \\
\hline Mozambique & 18.11 & 610 & 50 & 78.41 & 4 & 56 & 56 & 20 & 20 \\
\hline Namibia & 1.65 & 3600 & 10 & 82.54 & 1 & 64 & 64 & 22 & 13 \\
\hline Nicaragua & 4.21 & 1570 & 15 & 12.02 & 9 & 43 & 43 & 35 & 12 \\
\hline Oman & 2.31 & 10020 & 4 & 21.25 & 2 & 5 & 5 & 0 & 93 \\
\hline Pakistan & 131.5 & 1930 & 24 & 77.87 & 23 & 6 & 6 & 4 & 67 \\
\hline Rwanda & 8.6 & 950 & 50 & 2.50 & 29 & 18 & 18 & 10 & 32 \\
\hline Saudi Arabia & 18.73 & 9510 & 10 & 196.1 & 1 & 39 & 39 & 1 & 59 \\
\hline Serbia & 11.1 & 1000 & & 10.21 & 30 & 20 & 20 & 25 & 20 \\
\hline Somalia & 7.35 & 500 & 10 & 62.73 & 2 & 46 & 46 & 14 & 38 \\
\hline Thailand & 60.27 & 5970 & 11 & 51.18 & 34 & 1 & 1 & 30 & 31 \\
\hline Uganda & 19.57 & 850 & 57 & 19.97 & 23 & 25 & 25 & 30 & 13 \\
\hline UK & 58.3 & 17980 & 1.5 & 24.16 & 29 & 48 & 48 & 9 & 14 \\
\hline USA & 263.8 & 25850 & 2.0 & 916.67 & 20 & 26 & 26 & 29 & 25 \\
\hline Vietnam & 74.39 & 1140 & 36 & 32.54 & 22 & 1 & 1 & 40 & 35 \\
\hline World & 5733 & 5400 & & 1489 & 10 & 1 & 24 & 31 & 34 \\
\hline
\end{tabular}

$P \quad$ Population (millions)

NP National product per capita (US\$)

$\mathrm{Ag}$ Percentage of national product generated in the agricultural sector

Area Land area in millions of hectares

Ar Arable land as percentage of land area

PC Perennial crops as percentage of land area

MP Meadows and pastures as percentage of land area

FW Forest and woodlands as percentage of land area

Ot Other land types (e.g., sandy desert) as percentage of land area

- Source : CIA World Handbook 


\section{A Framework for Technology Analysis and Action $\mid 9$}

six billion people. If 1 million hectares of land is certified per year, at an annual cost of $\$ 10$ billion, this represents only $0.03 \%$ or 300 parts per million of the WDP. It is instructive to compare the cost as a fraction of WDP with two other parameters: the costs of medical care and other injury-related expenditures (which amount to about 10 parts per million of the WDP), and the injury rate (which is 10 per year per million people). These figures suggest that current demining costs are out of proportion with the scale of the problem, which gives a possible economic explanation for the failure of the world community to solve it. (However, these statistical measures do not include humanitarian factors, which compel us to consider new paradigms for a landmine solution, or a long-range, enlightened worldview.) The point is that it is clearly within the economic capability of the world community to shoulder this financial burden even using current demining methods, subject, of course, to political, national, and international priorities, but it is currently economically unattractive to do so. Unfortunately, a historical perspective of international action suggests that as long as costs remain so high relative to return on the demining investment, it is unlikely that the world community will make the necessary funds available, even if the other factors affecting such a decision were favorable. These estimates also show the pivotal role of the developed nations. If the developed nations get involved, financial resources can in principle be made available, whereas without their involvement, financial resources will almost certainly be inadequate. Because the developed nations and their industries have been responsible for the production of mines, as well as for their deployment in World War I and World War II battlefields, it is appropriate that they take a significant measure of responsibility for the post-conflict damage the mines inflict.
An intermediate model is to choose subregions where the financial burden can be shared with nonagricultural sectors. In this model, certification is carried out on a regional basis, rather than on a field-by-field basis. Since everyone within the given region is considered to benefit from certification, it is reasonable to ask them to contribute. The choice of which specific subregions to use must be based on the existence and effectiveness of administrative functions covering the subregion. These administrative functions must be sufficient to support efficient use of demining resources. The subregions for demining may not necessarily have natural geographical or the recognized political boundaries, although it is to be expected that demining would be administered most efficiently on a country-by-country basis. The financial burden can be more easily borne by a larger segment of the population than just the agricultural regions affected. Subregions of a country will on average have fewer resources to pay for certifying all the land in a country than the country itself can bring to bear. In this sense, choosing the entire country to bear the financial burden probably represents a circumstance where the combination of financial and administrative resources maximizes the cost-effectiveness of demining operations.

On a country-by-country basis, the income base is the national product, and the area involved can be estimated. The compromised land, probably a small fraction of the country's arable land, can be estimated from the number of claimed mines by using an average mine density. On this basis, poor countries have an income base of about \$1000/ha, while rich countries have about ten times this value (see Table 2). The increase in income base using the entire country rather than simply the agricultural sector of its economy ranges from about four for poor countries to about ten for moderately wealthy countries. Nonetheless, sharing the burden over the 
economy of the entire country will not make sufficient resources available to certify the land in less than 25 years.

Thus, while there are sufficient financial resources worldwide, only high-income countries can afford to demine or certify land. Kuwait is an example of a high-income country that seems to have solved its problem with abandoned landmines. Kuwait has apparently cleared most of the mines laid in the desert during Operation Desert Storm, but it has achieved this result at a cost of some $\$ 900$ million. Since most landmines are in moderate-income, low-income, or poor countries that cannot afford to reclaim their lands, it is necessary for high-income nations to become heavily involved and make funds available to these countries. Despite the wide publicity given to the problem, funds have not been made available on a large scale. The international response has been to provide education to reduce the risk of injury; to provide funds to develop cheaper mine detection and clearing technologies; and to provide a low level of funding for traditional demining, which is too slow and too expensive. But the international community has not yet come together to act effectively on this problem.

\section{Sustainable Demining}

The current method by which the international community provides assistance to regions making a transition from conflict to peace essentially involves four steps. Each transition has unique features, but there are some general similarities between transitions in different regions. The first step is to offer the combatants assistance in forming a cease-fire agreement that will pass the test of time. In Bosnia, this was the Dayton agreement of 1995, facilitated by President Clinton and the U.S. Department of State. After a lasting cease-fire appears to be in place, the second step is to deploy peacekeeping forces on a temporary basis to reduce the risk of a lapse in the cease-fire.
Such peacekeeping operations are usually carried out under the aegis of the U.N. Department of Peacekeeping Operations, UNDPKO. Peacekeeping operations usually involve actions to reduce the hazards of leftover ordnance and to facilitate peacetime activities by taking emergency measures protecting what is left of the physical infrastructure of a country. A transition from UNDPKO to the UN Department of Humanitarian Affairs, UNDHA, begins the third step. During this phase, the UN undertakes mainly humanitarian assistance, which can take many forms, but is directed primarily towards providing the essentials needed by civilians living in the former warzones, or by refugees. The fourth step begins when UNDHA discontinues operations and the local government assumes full responsibility. This is a phase of development economics characterized by reconstruction with financial assistance in the form of loans and grants from external agencies, and is little different from normal peacetime economic development and growth.

Landmines can be dealt with in any of these phases. In the peacekeeping phase, landmines are cleared mainly to protect the peacekeeping forces. In the humanitarian assistance phase, landmine action is carried out by a U.N.-sponsored mine action center (MAC), and tends towards ensuring first that civilians are protected as far as possible from injury followed by ensuring access to the essentials-food, clothing, housing, potable water, and medical care. Much of this humanitarian demining is conducted by external nongovernment organizations (NGOs), who are supported by charities, or perhaps by their own governments. Towards the end of the humanitarian phase, landmine action includes developing a capability to deal with landmines that can be handed over to the local government when the MAC is disbanded. This capability might include accurate maps of minefields; a force of local, trained deminers who can also train others; and a cadre of local individuals who 
understand the various options for dealing with mines, such as removal, burial, or sealing them off under concrete structure. It may also include a similar cadre trained to manage local demining activities. The pool of potential local managers may be very small if the region has a weak history of project activity. Thus the capability left behind by the UNMAC may not be maintained as an effective, efficient operation. After a war, local administrators may have more important things to deal with than landmines, and they are likely to have many problems to deal with besides working out a mine action plan-such as learning to talk with, work with, and trust their former military adversaries. Also, funds for demining will be made available according to the general economic activity and national product of the recovering country. It is a virtual certainty that the national product will be somewhat less after a war then before it. There is no magical reconstruction scenario that will greatly change this equation. Therefore, it is virtually certain that the recovering region will have fewer resources for demining than before the war.

The challenge of sustainable demining is to have a workable mine action plan that the local administration can follow after the humanitarian UNDHA phase is over. The plan must effectively protect civilians from injury and return compromised land to useful peacetime production.

In a humanitarian world, it is simply not acceptable to say that the mine problem was created by local people and it is therefore their problem. Developed nations and their industries are in some measure responsible and can be reasonably expected to give local populations some help, some framework for ridding their lands of this problem.

Sustainable demining requires not only that the local governments have the capability for effective mine action, but that they also possess the financial and management resources. A common practice by which external agencies provide humanitarian demining is to fund their own people and agencies to do work in the field. Thus, for example, the government of a European country might make a grant to some of its own domestic agencies to carry out operations in Africa. The government funds are spent domestically, so that little or no funds are passed to agencies of the affected country. This makes fine press regarding the funds expended on humanitarian concerns, but it does little to enable sustainable demining. One is reminded of the proverb: if you give a hungry man a fish he will be hungry again tomorrow, but if you teach him how to fish he will never be hungry again. Just so with the landmine problem. Its solution demands that every local region where there is a problem have the resources to deal with it. Costs will be lower, levels of diligence will be higher, and rates of clearing will be higher, than if the work were done by an external agent. Given the large areas of land currently affected, external agencies alone will almost certainly not succeed in the goal of creating a world free from landmines.

\section{The Nature of the Mined Areas: The Beginnings of a Solution}

Hand-laid mines. Consider first mines laid by hand. Mines are placed where they will protect assets or harass the enemy. In guerrilla actions, they are placed in areas where soldiers or people travel or near asset locations. In more formal confrontations, they can be placed to control areas of a battlefield, denying them to the enemy. They are not placed where people do not go, or where there is no asset. To protect one's own forces from accidental injury, they are usually marked with considerable margins. However, the process of marking minefields is far from standardized. There are many ways to reestablish the boundaries of the minefield after the conflict, ranging from anecdotal information about the combatants' actions, to location of injuries, to detailed maps of the minefields. Fear of injury will cause the boundaries to be 
placed well away from the areas where mines are believed to lie. Thus an area designated as a minefield typically contains several mined areas within it, but it is almost never the case that the entire area designated as a minefield is planted with mines. Mined areas within a minefield often take the form of groups of mines laid out in simple patterns such as a line, a " $V$," an " $L$," or a semicircle. Hence, only a small fraction of the minefield's area may actually be mined. While it is difficult to assess this fraction accurately, evidence from ongoing mine surveys indicates that it is usually less than $5 \%$ and may be as small as $0.1 \%$.

Artillery-laid mines. Minefields where mines are laid by artillery will have a different pattern from hand-laid minefields. Mines scattered by artillery will fall in a group covering an area representing the trajectory of the artillery shells as they release the selfactivating mines onto the surface of the ground. The individual mined area created by a shell will have a long ovaloid pattern. But it is nonetheless expected that after the conflict is over, the remaining civilians will set the boundary of the minefield well back from the known locations of these individual groupings, for fear of accidental injury. In view of the very large numbers of mines that can be scattered by artillery, it is likely that the fraction of the minefield covered by individual mined areas is somewhat larger for this case. Obviously, there can be no detailed maps of the locations of individual mines when they have been scattered by artillery.

This circumstance allows mine action to be divided into at least two steps: rapid survey to find the mined areas within the marked minefield, followed by action to remove, neutralize, or seal off the mined areas. Rapid survey in this case means using all applicable useful information, and in particular maps, as well as rapid mine detection methods. Clearing the mined areas involves the more standard concept of mine clearing technologies such as prodding or another appropriate method.
The implication for technology is that rapid survey methods may well be enough to bring the problem under control initially. If a general scan of a minefield can free $75 \%$ to $95 \%$ of the minefield area for safe use, the remaining mined areas can be cleared with traditional methods, cordoned off, or otherwise neutralized and rendered safe. The idea that rapid survey can bring the problem under control in the near-term shifts the focus for new technology away from actual mine detection and clearance in a potentially contaminated environment, to a process of verifying that no existing objects could be mines. This is a different but nonetheless equally challenging technical problem.

\section{What Constitutes a Mine?}

The problems caused by abandoned antipersonnel (AP) landmines are also caused by other munitions. Technically, a landmine is a device specifically designed to explode when activated by the close presence of motion, or by ground pressure. It does not distinguish whether the trigger is a soldier or civilian, and has no time-limit other than aging. Devices that adhere to this definition are not solely responsible for the landmine problem. Booby-traps, specialized improvised devices, and left-over ordnance such as cluster bombs and artillery shells are also found. These are all part of the same problem, and should all be included in the solution.

Booby-traps and improvised devices are relatively easy to construct. For example, a handful of plastic explosive, wrapped and surrounded by ordinary nails, and fitted with a detonator triggered by a pressure switch, is in fact a landmine to all intents and purposes. A hand grenade tied to a tree branch, with a push-pull trip wire attached to the pin, is also a landmine. A booby-trap can be constructed from materials commonly issued to soldiers. It is virtually impossible to prevent the emplacement of such devices by restricting access to the materials needed to construct them. Nonetheless, it 
takes more time to improvise a booby-trap than to emplace a mine specially designed for the purpose. It may be that booby-traps are more likely to be found in areas with vegetation, or buildings, rather than in flat open ground. However, for a variety of reasons, one expects the ratio of booby-traps to landmines to be small. From the point of view of contributing to the injury rate or requiring mine action to be neutralized, a booby-trap is indistinguishable from a landmine. Thus from the point of view of injury and mitigation, there is only a minimal issue with the strict definition of a landmine.

However, from the point of view of prevention of further use, or regulation of their use, it is prudent to define the term "landmine" sufficiently broadly to preclude the use of alternate devices that perform an equivalent function but that were not strictly designed to be used as landmines. For example, humanitarian law relating to landmines might define a landmine as any explosive device that simultaneously meets three criteria:

- It does not discriminate between soldiers and civilians.

- It is activated by motion, ground-pressure, or other short-range sensor.

- It retains its lethal capabilities long after the military action is ended.

International law should discourage the reckless use of mines by setting enforceable penalties. With this or a similar definition of what constitutes adequate physical evidence of reckless behavior, it would seem practical to make it criminal offense-a war crimefor soldiers, their commanders, and their governments to leave such a mine hazard behind after the conflict has ended. Wording such as this focuses on the risk to civilians, while allowing combatants flexibility to conduct operations during a conflict.

\section{Technology For Removing Landmines}

\section{Technology Overview}

It is well-recognized that current methods of land certification are too slow and too expensive, and that for some regions, suitable technology does not exist. Historically, landmines have been a concern of the military: it is only within the last few years that they have been recognized as weapons of terror, and that the humanitarian focus has become clearer.

An excellent comparison of the requirements for unexploded ordnance clearance as seen by the DoD was recently published by the General Accounting Office. It covers the missions of countermine, explosive ordnance disposal, humanitarian demining, active range clearance, and unexploded ordnance environmental remediation. (We prefer to use the term "land certification" rather than "humanitarian mine clearance" or "humanitarian demining" because it is more descriptive of the mission goals, as discussed below.) Each of these missions has needs for various functionalities such as detection, location, access, identification, neutralization, recovery, disposal, training, and breaching. While all these missions, each of which was compared and discussed by the report in great detail, clearly have the commonality of mine detection and disposal, land certification has substantially different features from the other missions. These differences make it harder for competing technologies to progress to the point where humanitarian goals will be accomplished, for reasons detailed below.

It is not sufficient merely to look at technical requirements. One must also consider the methodology, end-user needs and budgets, cultural factors, etc. The technology must always appear in an operational plan, and operational plans can be strongly influenced by nontechnical factors. (The situational 


\section{Landmine Policy in the Near-Term}

factor is very familiar to agencies seeking technologies for military missions.) Most scientists and engineers would agree that it is nearly always possible to devise a solution to any technical problem, given sufficient funds and time. But it will be a major challenge to do this for land certification, because the available resources (manpower and budgets) are so limited relative to the perceived need. For example, the military budgets of the developed world are currently around $\$ 500$ billion/yr, whereas the country GNPs in the affected regions amount to less than $\$ 5$ billion/yr. The disparity between the cost of meeting mission requirements and the funds available is much greater for land certification than for other mine-related missions. While the other missions have requirements that occasionally exceed those of land certification (for example, in the depth below ground level to be searched), those requirements exist only for a short time or over a small land area, and highly trained and skilled individuals are available to the mission. In contrast, land certification is a multidecade effort covering vast regions of the earth's land area, and most of the workers will be local labor, who may not be highly skilled.

To satisfy the local community, technologies for land certification must meet the highest landmine detection standards, effectively leaving no mines in the ground. These technologies must be highly versatile with respect to mine location and type, and operate at depths that are typically $20 \mathrm{~cm}$ but can be as much as 2 meters. They must handle many types of terrain, most of which is readily accessible, and only rarely work in areas unreachable except by foot. The cost per hectare must be such that even poor countries can afford it (that is, less than about $\$ 2000 /$ ha). The rate of land certification worldwide must exceed the rate of emplacement, currently (over-) estimated at around $100 \mathrm{ha} / \mathrm{hr}$. Since the worldwide rate must exceed this value by a sufficient margin to certify all compromised land in the world within 25 years, the worldwide requirement is over $100 \mathrm{ha} / \mathrm{hr}$. Land certification technologies as a whole must reach this performance level if they are to have an investment rate that the developed nations are willing to pay. (Eventually the beneficiary nations will repay all or part of this investment, but the resources to float loans to get the ball rolling must be available.) The technologies may involve broad area, coarse-resolution search methods, followed by finer resolution methods as needed, but they will certainly include closing methods where individual mines are positively identified and precisely located to within a few centimeters. The closing methods must be simple enough to make it easy to train local workers to use them with the required $\sim 100 \%$ effectiveness.

The key technical parameter of a demining technology with respect to economic analysis is the coverage rate. The cost of certification per hectare is:

Cost $=$ Expense $/$ Coverage .

The expenses include capital amortization and labor. Figure 3 shows the cost accrued per hectare by a technology that uses labor at a rate between $\$ 0.1$ and $\$ 100 / \mathrm{hr}$ and covers land at a rate between 0.1 and 1000 $\mathrm{m}^{2} / \mathrm{min}$. The solid lines indicate the contribution of the labor expense to the certification cost. Figure 4 is a similar graph that indicates the contribution of capital amortization expense to the certification cost. Every mine search and clearance technology can be assessed in this manner. In what follows, we look at the broad characteristics of technology areas and use these figures to determine their current suitability for costeffective humanitarian demining.

\section{Technology Options}

The first question in regard to technology is to understand the function of technology in the overall solution to the problem. There are several key roles for technology, which can broadly be described as follows: 
- Multiplicative Technologies. These multiply the effectiveness of the demining teams already in the field. For example, a $\$ 200 \mathrm{~K}$ flail can multiply the effectiveness of a team of 30 deminers by up to a factor of five, depending on the terrain and the actual density of landmines.

- Rapid Survey Technologies. These allow for rapid survey of areas suspected of being mined. They exclude as rapidly as possible areas labeled as minefields that actually contain no mines. Area surveys using multispectral imaging techniques would fall into this category, as would vehicles fitted with multiple sensors that can move rapidly through a suspected minefield. In general, these technologies use techniques that are rapid but give no detailed resolution of the mines. Their main function is to confirm as quickly as possible the absence of mines in larger tracts of land.

- Closing Technologies. These search for individual mines in regions where mines are known to exist. They identifying the presence of individual mines and indicate the safest way to dispose of them. These machines might include sophisticated image-processing capabilities or multiple sensors, and would sacrifice speed for detailed information on

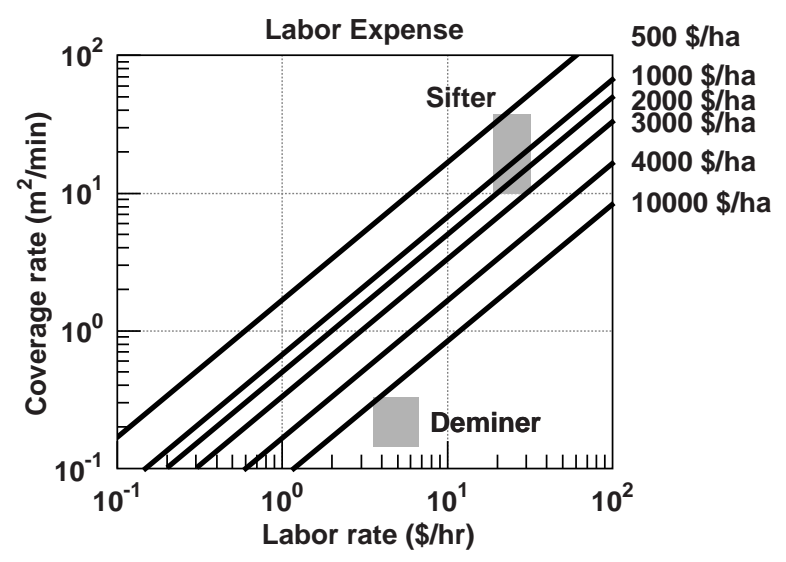

$\mathrm{N} / 1187-03$

Figure 3. Labor rate, coverage rate, and affordability. the subsurface objects that are being evaluated. Their main function is cover a small tract of land in painstaking detail.

In the near-term, there is a good chance that multiplicative technologies can be developed to assist demining operations and to cost-effectively increase the accuracy and speed of deminers. These technologies are relatively unsophisticated, well-developed but perhaps lacking in adequate field testing, and should be readily available from commercial operations. Technologies for the other functions are not readily available yet. They are more advanced and require more research and development before undergoing field tests. They will probably not be ready for field use in less than five or ten years.

Options for removing landmines fall into broad classes, characterized by the sophistication of the mine detection involved. One option that involves no mine detection and also has high clearing confidence is sifting the top layer of land. The machinery for this is either available today or can easily be created (without further R\&D and with minimal engineering and testing investment) in a short time period for risk reduction, and finetuned into an effective operational procedure.

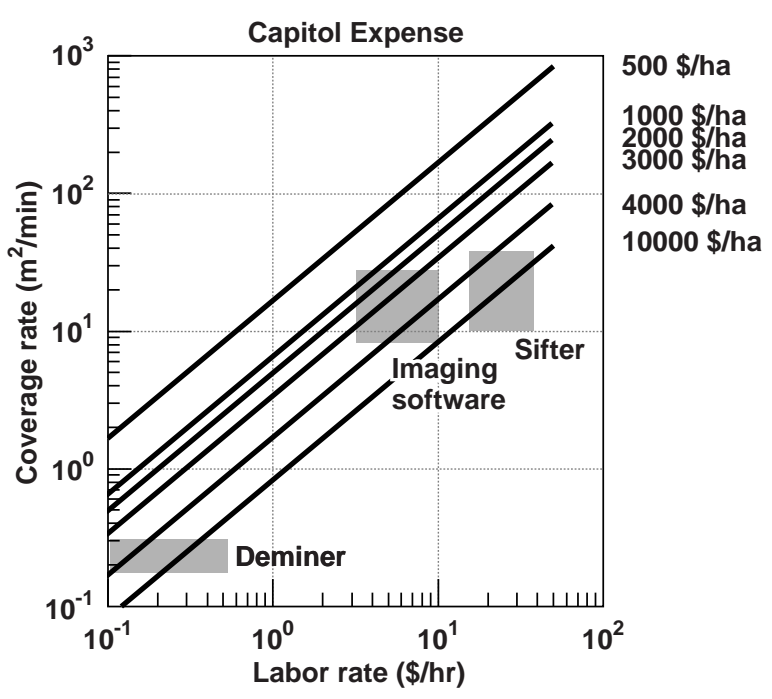

$\mathrm{N} / 1187-04$

Figure 4. Capital amortization rate, coverage rate, and affordability. 
It typically uses commercially available heavy machinery with extremely basic modifications. The cost of heavy machinery requires high clearing rates in order to be economically viable. Top layer sifting appears to come close to meeting the economic requirements. Another option is to detonate all mines with acoustic shocks or flails, but this has lower confidence, may not work on all mines, and may require some $R \& D$ to reach an acceptably high efficiency level.

Options for detecting mines either send out a probe that detects the mine directly, or detect something created by the mine that is accessible to aboveground machinery. Direct probes include manual ground-probing with bayonets, ground-penetrating radar, sonar, $\mathrm{RF}$ and ELF magnetic fields, and particles (e.g., neutrons). Indirect probes include infrared surface imaging and trace chemical detection. The current method, that of using prodders, is slow, and the fully loaded ratio of performance-to-cost for labor is about a factor of ten too high. For a function as complex as mine recognition, the "mine detection" elements in the prodder approach are the optical and tactile sensors of the human body, and software is represented by the human brain. (A human being is by far the world's least capital-intensive decision-making software.) For the other methods, not only is a detector or probe required, but also some kind of signal processing software to distinguish mines from clutter.

The software challenge for direct methods of mine detection can be formidable. In some areas the ratio of clutter to mines can be as high as a thousand to one. It is likely that most of the time spent in mine detection will be used processing these false positives. For example, let us assume that the mine detection efficiency requirement for land certification in a particular area is to leave less than one mine $/ \mathrm{km}^{2}$. If the density of mines is 10 mines/ha and the clutter ratio is $Q=1000$, there will be a million possible mines to evaluate per square kilometer, and less than one mine can be misidentified. If the target clearing rate is 1 ha/day, the software must process about 0.35 objects/s, and misidentify less than one in a million. If each object contains 10 Mbits of information, and assuming that the number of calculations required is about a thousand times the information provided, the data transfer rates must be at least $35 \mathrm{Mbit} / \mathrm{s}$, and probably near $1 \mathrm{Gbit} / \mathrm{s}$, and the microprocessors must run faster than 35 Gflops.

Image processing is compatible with highly parallel architectures. A Gflop system was constructed recently using sixteen Pentium 200 systems, at a cost of about $\$ 40,000$. Assuming a linear scaling, a 35 Gflop system would cost about $\$ 1.4$ million. The amortization costs for a 5-year lifetime are about $\$ 280,000 / y r$, excluding interest. This is to be compared to the value of the land cleared, say $\$ 1000 /$ ha at $1 \mathrm{ha} /$ day $\left(=20 \mathrm{~m}^{2} / \mathrm{min}=\right.$ $240 \mathrm{ha} / \mathrm{yr})$, which amounts to $\$ 240,000 / \mathrm{yr}$. Thus the current capital costs of image processing are close to the requirements even for heavily cluttered minefields. To put this another way, for a system with a five-year lifetime, in heavily cluttered environments, the technology must reach 1 ha/day processing 35 images/s with high reliability, yet using a computing capability significantly less than 30 Gflops. In five to ten years, the cost of a Gflop will probably be significantly lower, and greater computing power will be economically viable.

A related but separate challenge deals with the inevitable inaccuracies in the raw data provided by the probe hardware. The raw data must be accurate enough to permit unique and reliable identification of a mine. The issue here is the resolution with which the probe data describes the mine. If the "possible" mine appears as an "image" represented by three-dimensional data with 100 data points in each dimension to ensure adequate reliability, the probe information will contain 1 Mbyte $=8$ or 16 Mbits of information. The physical size of the mine is typically 10 to $20 \mathrm{~cm}$, so that for these assumptions, the spatial resolution is about $2 \mathrm{~mm}$. This 
wavelength corresponds to an acoustic frequency of about $500 \mathrm{kHz}$, and an electromagnetic frequency of 15 to $100 \mathrm{GHz}$, depending on soil moisture and other factors. Probes at this frequency do not penetrate more than a few centimeters into the ground and will not detect deeper mines. Thus, this level of resolution is well beyond current physical limits, and the associated computing costs will make the device economically unviable.

With 25 data points per dimension, there are 100 kbytes $=0.8$ to $1.6 \mathrm{Mbits}$ in the probe information, the resolution is $8 \mathrm{~mm}$, the frequencies are a factor of four lower, the penetration depth is a factor of four deeper (10 to $20 \mathrm{~cm}$ ), and the software processing speed requirement (and, presumably, its cost) is about a hundred times lower. The issue is whether 25 data points are sufficient to meet the reliability requirement.

The relation between resolution and image fidelity is a complex one that varies strongly over the terrain. Small-scale inhomogeneities in the soil moisture, and the presence of stones or voids can cause significant and unknown distortions in the probe data. A good analogy is looking into a pool of water and attempting to identify coins on the bottom when the surface of the pool is disturbed. As long as the image contiguity is preserved, there is a chance that, as you watch, several impressions can coalesce into an image that you can identify. But if the image of the bottom is noncontiguous, or is multiple, it is virtually impossible to tell even how many coins there may be, and identifying them or locating them precisely is out of the question.

What is the appropriate strategy for dealing with the identification problem? For each probe and software, there is a detection rate and an identification reliability. By using several probes in combination, it may be possible to improve identification reliability. For two uncorrelated methods of detection, the error rate is the product of the error rates of each, but if they are highly correlated, the error rate is not improved. An example of a highly correlated case is that where an acoustic and an electromagnetic method of detection both detect the same mine component, such as its casing. An uncorrelated case is where a direct, below-ground detection is used in conjunction with an aboveground, indirect method, such as chemical sensing.

On the other hand, sensor fusion will not increase the detection rate. The detection rate of two methods used in combination is in fact the slower of the two methods. Thus, from an economic perspective, sensor fusion does not increase the performance/cost ratios, and in fact it might reduce them slightly. But sensor fusion has the potential to greatly increase detection reliability. Thus it is a possible path to increasing identification reliability without increasing costs, but only so long as each sensor method is economically viable as a stand-alone system.

While the above discussion might seem to present a pessimistic point of view regarding the potential of new technologies to solve the problem at any price, that is not the intent. The future is, of course, unknown. But the history of science and engineering shows that almost any problem can be solved, given sufficient time and resources. The point is that an advanced sensor technology for detecting landmines reliably and economically will not be found in the nearterm, but will probably be developed over a longer time period, say ten years.

But people are still being injured and mines continue to be laid. What can we do in the intervening period, before suitable advanced technology is available to alleviate this problem? What can we do, using just the current financial and technical resources of the developed countries, about the landmine problem?

\section{A New Paradigm}

What would change the economic equation to allow nations that have landmine problems to afford to certify their land? The 
promise of new technology will likely not be realized for several years, although one hopes for an early solution. One option is to continue with education and current demining activities until a new technology is developed that radically reduces the cost of certification. Another approach is to reexamine the economic equation and the paradigm for certification that led us to the previous conclusions and develop an alternate paradigm, one that would allow significant progress to be made in the interim period while new technologies are being developed. What options exist for certification that bring it within the financial resources of the affected countries?

The answers are familiar to business executives: increase the value of the product (return on investment) and reduce costs. The value of the certified land can be increased by developing it, rather than leaving it in its original condition. Costs can be reduced by making certification operations more efficient, and by sharing costs with other related projects. In this new approach, some portion of the land would be developed, and the machinery brought in to carry out the development projects would be modified to give it dual use in both infrastructure development and land certification. Land certification costs would be reduced by using equipment that is already in place for infrastructure development, and by adopting efficient construction practices into the certification operation. The result is that since the beneficiary country will have greater earning capability as a result of the combined certification and development operation, the cost of certification is reduced. Another advantage of using heavy equipment is that the rate of certification will be much more rapid using machines rather than local deminers.

Most of the countries where landmines are an extant problem are either in transition from local conflicts and civil war to an incipient peacetime economy, or they have very recently made such a transition and are attempting economic growth. In both cases, long-term investment is in the essential infrastructure of peacetime economies, rather than in growing existing industries. Landmines are usually considered a barrier to making such investments. Land certification is an absolutely necessary step in such transitional and growing economies. It should become standard investment practice to carry out land certification as part of infrastructure emplacement, and for the goal to be certification of all the compromised land rather than just the land immediately targeted for infrastructure emplacement.

The greatest advantage of incorporating mine action into infrastructure emplacement can be had by electing to emplace the new infrastructures in areas where mines are known to be a significant problem. This policy runs counter to the idea that minefields should be roped off until a suitable inexpensive means of clearing them has been found and then returning them to their original pristine condition. Rather than avoiding minefields, one should choose to make investments precisely where the minefields are located. For example, the first roads to be developed and improved should be those that are known to be mined, or to run through minefields. Fields with a high density of mines should be targeted for commercial centers, factories, and new towns. In this way, the heavy earthmoving equipment that is a normal part of infrastructure emplacement will be there and can be used (with appropriate modifications) to clear the land of mines during the first stages of construction. The principle is to arrange for the income-generating potential of the improved land to increase with the number of mines and with the injury hazard in the area prior to development. Minefields should be considered the first target of opportunity, not the last: the more mines there are in a region, the greater the investment should be in development there.

Giving preference to mined regions in prioritizing the allocation of development resources will lead to pressures to inflate the extent of the local landmine problem by 


\section{A Framework for Technology Analysis and Action 19}

potential recipients. However, such exaggeration will become recognized as the claimed mined areas fail to produce significant mines or as other inconsistencies appear. Thus distortions of the resource allocation arising from inflated or otherwise inaccurate assessments of the problem will tend to be corrected as land certification proceeds.

Roads are a good example of application of this policy. Roads are essential to trade and economic development, and keeping critical routes mine-free is a high priority. At present, clearing roads is carried out by the standard, painstaking process of local deminers with long flat-bladed knives prodding the ground, perhaps with some assistance from mine-detectors or machines to clear vegetation on the roadside. This process is slow and costly. Rather than seeing this exclusively in terms of demining that returns the road to its prewar condition, it should be seen as an opportunity for infrastructure emplacement. Critical roads should be widened and paved and rendered capable of carrying the planned traffic expected as part of economic growth over the next 25 years. Building a modern arterial road requires heavy earth-moving equipment, such as graders, loaders, bulldozers and back-hoes, as well as machinery for laying a road surface, building bridges and culverts, and possibly adding communications and power cables. It is in the nature of roadbuilding that the top layer of dirt is removed. It would be straightforward to add a sifting step that would trap all objects large enough to be landmines or other unexploded ordnance (other than small arms rounds). The roadbuilding machinery involved is large and heavy and could be easily and inexpensively modified to withstand the relatively weak blasts from antipersonnel mines. The project completion time would increase by a small factor, but the time spent on mine clearance is very much smaller than the time involved using the historical method. The result is a mine-free highway that meets the needs of the local economy for the next 25 years.

The costs of demining by this method include the cost of the equipment modifications plus the cost of the increased time the extra step takes in the roadbuilding project. The second factor (increased time) is by far the greater cost. Using existing machinery for demining rather than human beings has several advantages. It greatly increases the rate of clearance, it reduces the risk of injury, and in general it will cost less then standalone certification per hectare of land cleared by taking advantage of cost-sharing and increased efficiency. It will also make deminers themselves more efficient. The cost of large earth-moving machinery can be estimated by methods well-known to contractors, which are summarized in the manufacturers' performance handbooks (e.g., Caterpillar Performance Handbook, Edition 27, 1997). For example, a large loader weighing about 200,000 pounds and costing about $\$ 1$ million is capable of moving 10 to 25 cubic meters of earth per minute. If such a loader is used to load the top $100 \mathrm{~cm}$ of earth into a sifter, the loader will process the top layer of earth at a rate of 600 to $1500 \mathrm{~m}^{2} / \mathrm{hr}$, or 1 to 2.5 days/ha. Including amortization of the capital cost and owning and operating expenses, such a machine costs roughly $\$ 250$ /hr to own and operate in the U.S., and somewhat more in remote locations. (The actual costs are heavily dependent on the details of the job undertaken, and its location and accessibility. We give these estimates here strictly for illustrative purposes.) At $\$ 250 / \mathrm{hr}$, the cost of sifting the top meter of earth during an earth-moving project adds around $\$ 2000$ to $\$ 5000 /$ ha to the cost of the project. Sifting earth in this way costs almost a factor of ten less than current methods.

The rate of certification using heavy machinery is much more efficient in the use of people. Each machine and operator covers roughly $1000 \mathrm{~m}^{2} / \mathrm{hr}$, so achieving a worldwide certification rate of a million hectares per 


\section{Landmine Policy in the Near-Term}

year (500 ha/hr) would require only 5000 machines and 5000 operators. To cover land at the same rate that it is being compromised (10 to $100 \mathrm{ha} / \mathrm{hr}$ ) would require 100 to 1000 machines. The capital cost of these machines is roughly $\$ 1$ million, so the capital investment in machinery to match the rate land is being compromised is roughly $\$ 1$ billion. With cost-sharing between developed nations, this figure can be significantly reduced.

Sifting the top layer of earth has several attractive features. The first is that it gives the subsequent land users high confidence that no mine has been missed. Second, the depth to which land can be certified can be varied widely. To certify land to a depth of 2 meters takes twice as long and costs twice as much as going to a depth of 1 meter. No other method of certification has this flexibility or can reach so deep with such high confidence that all mines have been found. Further, it is not sensitive to clutter and other materials; it works on all types of mines and UXO; it works on most soil and terrain types; and it returns the sifted earth as topsoil which has been aerated and is suitable for cultivation. For roadbuilding, cultivation is not relevant, but for certifying minefields close to roads that are being built, this can be useful.

Sifting the top layer of earth can be accomplished quite rapidly if the earth is flat and is broken up for easy loading. This likely to be the case during large construction projects such as roadbuilding, or for land that has been in agricultural production until recently. If the ground is not already broken up, a second step must be added before sifting, to facilitate loading.

Another example involves farmland. The productivity of farmland can be increased by introducing irrigation systems and wells, fertilizer and pesticide plants, factories for farm implements, supply roads and transport vehicles, new crops that are more profitable or that support more cattle per hectare, and so on. The equipment to emplace this type of infrastructure also involves heavy earth-moving equipment, which can be inexpensively modified to sift the earth that is moved, just as for roadbuilding. A further example involves clearing vegetation. Landclearing equipment exists and can be brought to bear on the problem. In some cases, the vegetation has value and can be sold to help defray the cost of demining.

While these estimates of the performance and costs are indisputably inadequate for business or job planning, they do suggest a method for land certification, one that uses current technology and at the same time lies within the financial resources of the mined regions and the willingness of the international community to make support available.

\section{Certification and the Environment}

One factor in land certification is the local community's views regarding an acceptable level of environmental disruption or damage. There is a natural desire of local communities to preserve the beauty of the land as well as the environment. In places where development is planned, local communities as a whole will have accepted disruption of the environment as part of the price of development. However, in areas where development is not planned, communities may wish to avoid disruption of the environment. Yet in the near-term there is no method of certifying land to a depth greater than $20 \mathrm{~cm}$ without disturbing it in some manner. Thus maintaining open land in a relatively pristine condition forces deminers to use the present inefficient and labor-intensive methods.

To what extent should land certification be permitted to cause environmental disruption? This question addresses by far the greater part of the compromised land, which includes farmland, cattle ranges, forests and woodland, sand dunes, and rocky outcrops. Like present techniques, most of the advanced technologies being pursued for land certification leave the land untouched. It is not certain that suitable, high confidence advanced nondestructive methods will be 


\section{A Framework for Technology Analysis and Action $\mid 21$}

available within the next five or ten years. In the near-term, it might be advisable to consider mildly destructive technologies. One such procedure is stripping and sifting the top layer of the ground, in effect treating the land as a strip mine, where the "ore" is mines and other unexploded ordnance. Is this solution environmentally acceptable, and can it be cost-effective?

Strip mining methods such as those used in gravel pits generally cover a limited area as deep as is profitable to extract the ore. The mine is considered unsightly by many communities - a scar on the earth - and because it is present for a long time, it can be the focus of efforts to mitigate environmental damage. On the other hand, for land certification, the objective is to cover a lot of ground area to a shallow depth. For example, to cover a large area where no development is planned, envision an area $2 \mathrm{~km}$ long by about 200 meters wide, containing machines that remove the top layer of earth from one long side, sift it, and replace it at the other long side. The whole area moves over the terrain at about $100 \mathrm{~m} /$ day, covering about 20 ha/day, or 7500 ha/yr.

The terrain the operation leaves in its wake is, of course, bare earth materials, without vegetation. The terrain will slowly revert to a natural state. If rocky, it is already in its natural state. If it was grassy cattle range, the grasses should reappear within a year. If it was wooded, trees and other vegetation will reestablish themselves over a period of a couple of decades. Reforestation can be used to speed the land's return to its preconflict state. The environmental disruption will last at most a year for rangeland, a short time that is an arguably acceptable inconvenience to endure in order to have the land certified mine-free. For forest and woodland, the recovery time is long in comparison to the near-term period we are considering here, and this is in itself a reason to cover these terrains by a nondestructive method, perhaps even delaying treating them until a suitable advanced nondestructive method is developed.
The cost of this operation is somewhat higher than the cost of sifting during an earth-moving project, because access roads will be required for personnel, small vehicles, and necessary supplies, and because the terrain may be difficult. The volume of earth treated is about $60,000 \mathrm{~m}^{3} / \mathrm{hr}$, which requires about 100 sifting machines of the type alluded to earlier, as well as other machines to break up the ground and clear vegetation as necessary.

\section{Certifying Difficult Terrain}

Finding mines in terrains that are not flat and vegetation-free is more difficult. More difficult terrains include thick or brushy vegetation, forested regions, regions under water (such as rice paddies), waterlogged regions (such as peat bogs), and areas where mines have been covered by gravel or rocks. The presence of strong inhomogeneities in the ground, or of water, scatters and blocks electromagnetic radiation, making such methods less reliable or even unusable. Moreover, in dense forests, mines can be placed above ground yet be well-hidden by the vegetation. At the time of writing, this study has not identified suitable practical methods of mine action for difficult terrain that do not destroy the environment. For example, Menschen Gegen Minen (MGM) uses a protected mulcher to clear roadside vegetation in Angola. And the Cambodia Mine Action Center (CMAC) has tested burning the forest to clear mines at the edge of the canopy in Cambodia. Effective nondestructive methods for dealing with denser vegetation remain to be found.

\section{The Last Mine}

As mine action proceeds and the number of mines diminishes, detection difficulty might be expected to rise. At some point, mine action does not reveal any more mines, and the mined area is cleared to the confidence level of techniques used. What is the effect of 
the diminishing number of mines on the certification rate and how can the neutralization of the last mine be ensured?

In effect, coverage rate is virtually unaffected as mines are neutralized. Initial survey methods do not remove the mines at all, but define mined areas within the minefield. While several passes may be needed to reach the desired confidence level, and several methods, the time taken to do this does not depend on the number of mines. Survey work of this nature focuses on the regions where there are no mines, and seeks to find those areas before concentrating on the mined areas. Thus, mine survey rates are not affected by mine density.

Mine action can take several forms. Burying the mines under concrete or deep underground also does not depend on mine density. Removing the mines from the ground requires painstaking search methods to find them. Usually the clearance method involves a single pass, for obvious reasons. After that single pass, the mines are all neutralized to the confidence level of the method. Mine density is usually low enough that most of the time spent in clearing mined areas is spent searching for mines, not disposing of them. Thus, mine density does not really affect the clearance rate.

In some areas, the weather can cause substantial ground motion. Mines can be buried and re-exposed. Examples can be found in areas with sand dunes, such as Kuwait or North Africa, or areas subject to intense rain, such as the two Koreas. In areas where mines "swim," even the most carefully prepared maps are useless after a time. The swimming of mines in North Africa is well-documented and represents a significant problem for demining. If the mines can be moved by weather, it is necessary to cover the region several times over a period of several years to be sure that no more mines will reappear. In Korea, there is evidence that mines have been washed off hillsides into rivers where they cause injuries downstream. If possible, minefields subject to swimming should be cleared as soon as possible after emplacement. In Kuwait, the minefields have been cleared, but the mine action groups are remaining in the field to ensure that no swimming mines are re-exposed.

Getting the last mine is therefore just the same as getting the first mine in most cases. In those areas where mines swim, such as sandy deserts or monsoon regions, it is necessary to act several times over a period of several years to be sure that the minefield is rendered safe.

\section{Construct for Worldwide Action}

\section{Prioritizing Land for Certification: The Reconstruction Plan}

The near-term goal of land certification must be to stabilize local communities with respect to food, employment (however weak), and safety. The majority of mines and mine injuries occur near local population centers or assets of potential military value, and the first priority of land certification must be to create a buffer zone of safe land around the local population centers sufficient to provide food, safety, and economic activity. For example, take a local farming community located in flat rangeland or cropland. Considered apart from the rest of the region, this local community of $\mathrm{n}$ people requires survival land of area $A=n / L$ where $\mathrm{L}$ is the number of people each hectare can support. Additional land is required for economic activity, and safe roads are required to other local communities. Over a larger region, there will be larger population centers that import food, and that also support local businesses. The local farming community must have enough land to support some portion of the townspeople as well. Thus the area that must be certified is roughly $\mathrm{fn} / \mathrm{L}$, where $\mathrm{f}>1$ represents the additional land required to provide food to local neighbors and for other community uses. 
In the aggregate, the total land requirement is simply $\mathrm{fN} / \mathrm{L}$, where $\mathrm{N}$ is the total population of a subregion, including villages, towns, and cities. Not all of the land area needed will be compromised by landmines. The challenge to local governments is to draw a map of land utilization that provides the necessary land to support the population, and at the same time uses as little compromised land as possible. The nearterm goal for land certification is to certify as safe just that portion of compromised land needed for local use. This is the highest priority for land certification. The next highest priority is to reclaim land where the injury rate is highest, and so on.

The need for accurate maps cannot be overemphasized. The disproportion between the cost of certifying land with currently available demining options and the present funding situation will force local governments and their development sponsors in the developed nations to be extremely efficient and frugal in deployment of available demining resources. The local government may have several social and economic issues to address, such as:

- Rebuilding the food supply.

- Caring for returning refugees.

- Rebuilding industrial capability.

Rebuilding the Food Supply. Civil conflict and minefields disrupt the production and distribution of food and other essentials, reducing them to below preconflict levels. Restoring the food supply requires certifying land for agriculture and raising cattle, as well as restoring supporting businesses such as farming tools and fertilizers, if these are involved.

Caring for Returning Refugees. The demographics of local populations are altered, sometimes radically, by displacement of local peoples from their land and villages. Such infrastructure as may exist is inevitably strained by the relocation of large numbers of displaced persons. The solution is usually a combination of improving the infrastructure for supplying essentials, repa- triating families to their homelands, and providing equivalent, temporary living space for them. Safe land and safe living accommodations are necessary if a sufficient number of refugees are to return. Also, adequate medical care needs to be provided.

Rebuilding Industrial Capability. Even this foreshortened description of the issues of reconstruction shows very clearly that mines can and usually do affect every aspect of the life of the area. Every region is unique, not only with respect to the technical problems of removing landmines but also with respect to socioeconomic factors. The information needed to determine how to best use a demining capability essentially involves the entire plan for reconstruction of a postconflict region. For it is only within the context of that plan that demining prioritization can be carried out. The reconstruction plan will indicate, in order of priority, the nearterm priorities. This may be refugee repatriation, infrastructure restoration, or simply the temporary provision of essential subsistence support. From these priorities, a prioritized map can be drawn of areas needing demining. This map provides a well-defined technical and economic information base. For example, from it, a contractor can estimate the cost of certifying the land, and the demining cost component of reconstruction can be estimated by potential investors.

As part of this process, the local government must determine how to use the reclaimed land, and designate areas for infrastructure development to provide the income to defray the costs of land reclamation. As we discussed above, the best areas to select for infrastructure development are precisely those where mine density is highest. This will minimize the cost of demining. Then, before land certification begins, another contract to fund the development is made with a resource based in the developed nations. Infrastructure development is allowed to proceed, and as it proceeds, the highest priority land is certified as part of the development activities. Certification 
would be carried out by skilled, for-profit specialty contractors using demining techniques that fall within the desired cost envelope. The specialty contractor would most likely be another developed-nation enterprise, one that uses local resources as appropriate to provide local income. Within this overall scheme, there is ample opportunity for the developed nations to provide humanitarian support outside the scope of the business activities. One such method would be to provide insurance against cost overruns, or to provide grants or low-interest loans to assist the local people through any period of financial hardship.

In this connection, it is noteworthy that decision-making tools for selecting technologies and approaches for clearing mines from well-defined areas have been developed in both the U.K. and in Australia.

\section{Scale and Nature of Worldwide Effort to Eradicate Landmines}

As discussed above, the publicized technical parameters describing the mine problem have been used in the past to set the scale for a solution, and the result is discouragement that any effort we can reasonably expect to mount will actually make a significant difference. But we would claim that this conclusion is incorrect. We argue that the scale of the solution is in fact within the financial resources and the political will of the developed nations.

We argue four main points:

1 . The scale of the human problem is represented by the injury rate and the area of land excluded from use by the perceived presence of landmines. The number of landmines actually present is basically irrelevant to these documented facts.

2. On the other hand, the scale of mine action required to prevent injuries and return the land to use is strongly affect- ed by the actual number of landmines, and in particular by their distribution within the minefields.

3. The number of mines is considerably lower than the publicized value, perhaps by as much as a factor of three.

4. The fraction of the suspected mined areas actually occupied by mines is quite small, perhaps lower than $10 \%$.

The most efficient action is therefore as follows:

- Prepare detailed maps of the suspected mined areas to identify the areas probably free of mines within the suspected minefields. Acquire or apply existing technologies for making this process as rapid and efficient as possible.

- Acquire multiplicative technologies to increase the effectiveness of mine clearance.

- Acquire rapid survey technologies to return mine-free areas to use as rapidly as possible.

- Set up an international force of deminers and support organizations.

- Set up a practical construct for international cooperation by the developed nations for financing and otherwise supporting deminers and support organizations.

In the remainder of this section we discuss these ideas in more detail, and use them to set the scale for international action.

Assume 30 million mines, and a 10\% occupation rate by area for the suspected mined areas. Mine survey is faster and less expensive than mine action on the mined areas, and we may take the mine survey costs to be about $10 \%$ of the mine action cost. Then the required demining force would be perhaps $1 / 20$ of the gross estimate, or about 15,000 deminers worldwide, which would cost between $\$ 100$ million and \$200 million a year to field. If this cost were shared equally between the seven industrial nations, the cost to each nation would be $\$ 15$ million to $\$ 30$ million, easily within the discretionary budget of an advanced industrial nation. 


\section{A Framework for Technology Analysis and Action $\mid 25$}

The benefit of mine action would easily repay this investment in reduced costs of reconstruction aid, refugee assistance, humanitarian aid, and economic production of the recovering regions.

Thus, by concerted international action, the industrialized nations could field and support a force of deminers at costs well within their discretionary budgets.

A significant force of deminers would have to be drawn from a pool of qualified individuals from the developed nations. The natural pool to provide this force is retired military officers and explosive ordnance disposal (EOD) experts. This pool not only has experts, but experts who already have partial financial support. Demining would be an excellent use of this group's expertise, and it would be costeffective and politically attractive. This idea was first made known to me by Frank Cook, chairman of the U.K. All-Party Landmine Eradication Group. It could be an enabling concept for an international solution.

To be effective, demining or certification operations will require a substantial campaign. The technology resource has low coverage rate and is expensive relative to the economic value of the reclaimed land. An efficient campaign will need a rigorous test for demining priorities, based on a land-use policy. The land-use policy will flag minefields according to their value for the various needs the recovering country may have. This will include rehabilitation of local population and returning refugees; access to infrastructures such as bridges, electric power, potable water, etc.; road opening and transportation development; and agriculture and nutritional needs. If demining operations are carried out without the guidance of a larger plan, scarce resources will likely be used inefficiently, thereby slowing the recovery and unnecessarily increasing its cost. The reconstruction plan, land-use policy, and a mine action plan coordinated with these plans are extremely important to efficient mitigation of the landmine problem worldwide.
An effective demining or certification plan will require extensive data. It is well beyond the scope of this document to attempt to define a framework for land use policy in regions recovering from civil conflict. However, the need for a land use policy will certainly force land use planners to compile adequate data to ensure mine action effectiveness. The data that is required can be described as the need for accurate maps of economic factors affecting development and reconstruction. Relevant socioeconomic factors include the following:

- Population Distribution. Urban and rural population figures.

- In-Country Skills. Trained skills such as medicine, engineering, agriculture, management and planning, finance.

- Minefields. Boundaries of dangerous areas, and individual mined areas within the dangerous areas; proximity of mined areas to populated areas; classification by terrain, vegetation, class of mines emplaced.

- Food Production and Imports. Agricultural production capability, pre- and postconflict.

- Infrastructure. Agricultural machinery, electricity, potable water supplies, industrial production (if any), housing and clothing, roads and transportation capability.

Also, an effective demining or certification plan will require strong in-country leadership. One clear aspect of mine action management is the fact that it must be balanced against many other pressing issues of a recovering region. These concerns will involve security for the remaining civilians and returning refugees, and the establishment of trust between previous military antagonists so that a truly countrywide administration can be formed. In many countries, mine action is too insignificant compared to these other issues to merit the attention from local administrations that it needs. However, once the process of establishing (or re-establishing) a stable peace- 
time economy is under way, then issues such as mine action can rise in priority. It will be part of the international community's responsibilities for many decades into the future to work diligently to ensure that mine action will have an appropriate priority for local governments.

Mine action, like any element of a recovering country's agenda, will require statesmanship and administrative and management skills. In a recovering region, such management skills may be scarce. A poor country may have had little need for the kind of management skills required to run a business in an industrialized nation. While such management skills may be reasonably assumed in the industrialized nations, it is less certain that an adequate cadre of trained individuals can be fielded where mine action is required. Development of management skills as a national in-country resource will occur naturally as reconstruction and other economic development proceeds. But it may well be necessary to train in-country managers, especially in regard to meeting the accountability requirements that are now common in industrialized business.

In-country mine action managers will be responsible for maintaining accurate data bases on minefields, coordinating mine action with other reconstruction and development activities, and meeting documentation standards for accountability oversight. They will also be responsible for in-the-field mine action, including mine surveys, mine clearance, and mine neutralization. And they will manage the interface with the international community in mine action matters. At the same time, the international community will require efficient management to:

- Coordinate the many facets of worldwide mine action.

- Assist the development of better technologies for mine action.

- Set up and monitor international technical standards for mine action.

- Arrange for efficient information sharing.

- Monitor in-country compliance.
- Manage international budgets and arrange international financing.

- Execute international agreements on landmines.

The size of the worldwide effort will be determined by international agreement. At this time there are no international agreements specific enough to determine the scale of the worldwide program. Nonetheless, many of the elements of such a program are already known. It is almost impossible, in this kind of program, not to have a large bureaucratic element to manage the interfaces between the many organizations involved, both government and nongovernment. This brief review of the scope of the supporting administrative or management functions involved for efficient worldwide mine action will perhaps serve to emphasize the importance of setting the program up prudently. At the present time, there does not appear to be any-even partially coordinated-effort to plan worldwide mine action.

\section{World Demining Organization?}

The scope of the worldwide effort just outlined further serves to emphasize the differences between humanitarian mine action and military mine actions. The humanitarian area involves many factors that are absent from other mine action areas. Humanitarian mine action is clearly worldwide in scope, in regard to the large number of countries that have mines, the great variety of local cultures involved, the governments and NGOs that support mine action, the United Nations' role, the ICRC role and large number and variety of potential funding arrangements, and the international nature of the technology development effort. The uniqueness of the humanitarian area, together with its worldwide scope, strongly suggests that a worldwide organization be formed to manage all the complex aspects of the landmine problem. There is a strong analogy here with the World Health Organization. Landmines have much in common with diseases: they 


\section{A Framework for Technology Analysis and Action $\mid 27$}

can strike virtually anywhere without warning, they have significant health impacts, and their eradication obviously engenders strong humanitarian support worldwide.

The function of a world demining organization would be to act as a vehicle for implementing and facilitating the international cooperation necessary for landmine eradication. (Here we use the term "landmine" in its more general sense to include any device that causes post-conflict injury, as discussed above.) Such an organization would facilitate rather than lead, and would essentially support an international demining commission formed from representatives of the sponsors of the worldwide demining campaign. It would have a board of directors, a full-time staff of deminers, mine action managers, financial officers, and trainers, and would be capable of providing access to technology as appropriate. Its form, size, and bylaws would be established by agreement between the sponsoring governments. Such organizations are at considerable risk of becoming politicized, but there are models whereby they can function effectively, such as the ICRC or WHO. The potential advantages of such an organization, if it were successfully managed, are great enough to motivate further study to establish a construct whereby it could play an effective, positive role in landmine eradication.

\section{Proliferation and Growth Abatement}

Another important area for new technology to address is controlling the spread of landmines. It is clearly a high priority to reduce the emplacement rate so that land can be certified significantly faster than it is being compromised. Abating the growth in landmines is a complex political issue, but technology can indeed play a role here.

A post-conflict landmine problem is created whenever mines are laid with inadequate maps. The most common circumstances in which this occurs are civil conflicts. Mines are used as a "sleeping sentry" to guard assets that one faction wishes to deny to their opponent, often because they do not have the resources to protect them any other way. A lack of accurate maps can be due to a fundamental lack of discipline by the mine-layers, or to a lack of resources. Even if maps are made, in some circumstances mines can move. The opponent can move the mines to a new location a few yards away to turn the minefield against the mine-layers. If the mines are laid in sand or muddy terrain, over time they can be moved by the weather. But fundamentally, lack of sound military practice has created the greater part of the landmine problem. During a conflict, an undisciplined army is not concerned with the unsolvable post-conflict problem it might be creating, nor with the risk that its own mines will deny it access to the same assets. An army that owns mines will certainly use them, and if it is undisciplined, it will cause a post-conflict landmine problem. Intervention in this process will almost certainly be unsuccessful, even when it is feasible.

Much of the current international activity in landmines centers on controlling their use. Unanimous support for a landmine ban does not yet exist; there remain disagreements as to how this is to be achieved. Clearly a ban not universally undertaken leaves the signatories at a disadvantage. Even if a ban is achieved, the risk is that rogue nations will not respect it, or that the devices covered in a ban will be incomplete. In either case, devices functionally equivalent to mines will continue to be deployed and contribute to human suffering. A ban on landmines per se does not eliminate the problem, although difficulty in purchasing landmines will slow the emplacement rate. There is some risk that once a landmine ban is in place, the signatories can use it as an excuse for avoiding further action by claiming they have already solved the problem because landmines no longer exist. After a landmine ban, further action is required to eliminate landmine stockpiles and to investigate 
methods for dealing with "rigged" devices made from components that are still legitimately manufactured and sold.

\section{Future Military Use of Landmines}

Making mines easier to clear post-conflict also makes them easier to clear during a conflict. The function of mines is to impose a "keep-out" zone on the enemy. The military purpose is to control the battlefield, or to separate opposing armies or even mutually hostile nations (such as the two Germanys during the Cold War). The military value of denying the enemy access to certain areas or slowing its progress is indisputable. No technique does this as effectively or inexpensively as mines. Any proposed action that reduces mine effectiveness will also reduce the ability of armed forces worldwide to fight wars, and will probably result in increased losses and casualties. The challenge is to make minefields easier to neutralize post-conflict, without reducing their military effectiveness.

There are three options for avoiding the emplacement of large numbers of long-lived devices. The first is to arrange for all landmines or landmine equivalents to have a self-destruct, or self-deactivation feature, or a coded transponder that can be used to identify the device. Electronically controllable mines pose a significant security aspect associated with protection of the transponder codes. The second option is to replace landmines with local detectors that identify the target and inform a soldier some distance away, who then attacks the target by any weapon of choice. This is essentially a mine with a man in the loop (MITL). Such detectors might be arrays of crossed infrared laser beams, or simple proximate motion detectors.

The countermine tactic of surreptitiously rearranging the enemy's mines has been encountered in Southeast Asia. In response, some commanders adopted the MITL approach, using a remotely activated clay- more mine, emplaced and removed each watch. This was evidently found to be effective in establishing and maintaining a perimeter. It seems reasonable that an MITL approach using weapons that are periodically rearranged might be an effective alternative to the use of mines in many circumstances.

These advanced technology options are possible for a wealthy army, but may be beyond the reach of combatants locked in a civil war in a poor country. However, it is not the armies of the industrialized nations that need an alternative, but the resourcestarved armies in poor countries who can afford a minefield of $\$ 3$ mines but not a $\$ 1,000$ remote detection system and the soldiers to man the remotely activated weapons. It would be a tragedy if the desire for alternatives for AP landmines resulted only in further business between high-technology companies and rich military customers, leaving the less well-endowed armies with no real alternative to the \$3 landmines they now use.

A third option for avoiding long-lived mine emplacement is to develop mine detection equipment that will detect any type of lie-in-wait explosive device. Even if the formidable technical challenges of detection could be overcome, the possession of such technology by the opposing army would make unattended minefields completely ineffective.

It has been argued that the requirements for humanitarian mine clearance are quite different for those in combat situations, and in particular that the clearance rates needed for humanitarian demining are slower than those for combat situations. This assertion is not quite accurate. Sustainable demining requires high clearance rates at high confidence levels to be affordable. Typically the desired rates are over $1000 \mathrm{~m}^{2} / \mathrm{hr}$. For breaching, this is inadequate, but for countermine against unattended minefields, it may be adequate to allow an alert enemy to completely rearrange a minefield during darkness or during a short temporary 
absence of the troops guarding the minefield. Thus, for minefields laid to protect assets or troops, detection technologies adequate for sustainable demining are also effective in countermine operations.

In protracted civil wars, a ban on landmines may have little effect on the problem, because there is time to construct and emplace landmine equivalents to protect assets and troop positions. However, a ban on artillery-launched or air-launched landmines may be effective in preventing large numbers of mines from being strewn indiscriminately across the battlefield. Such a ban would have to include a sufficiently general definition of the term "landmine." Instead of a general ban on landmines, it may be more useful and more practical to ban specifically just those weapons of war that distribute mines at a rate faster than a single soldier can emplace them.

In summary, it appears that there may be some options that are less expensive than (and equally effective as) landmines that poor armies could use, and that would not leave the area covered with shallow buried mines. Research in tactics and strategy for dealing with mine-clearing methods adequate for sustainable demining appears warranted. Even if the technologies are not developed in the near future, such research could lead to effective alternatives to the use of landmines, thereby reducing or even eliminating the incentive to use them.

\section{Conclusions: Landmine Action Policy Implications}

The following areas must be taken into consideration when approaching the landmine problem:

- Prioritization.

- Financial support.

- Technology development.

- Maps and other supporting data.

- Other recommendations.

Each of these is discussed in detail below.

\section{Prioritization}

The most significant near-term benefit would be achieved by integrating a landmine clearance and land certification plan into all reconstruction plans after civil conflict. Indeed, since the mine problem is likely to be a long-term one, it would be beneficial to have an international agreement that all loans and grants for economic development should include a mine clearance and land certification plan. The same requirement should be included in humanitarian funding for demining projects, so that scarce demining resources can be used most effectively in preventing injuries and promoting a peacetime economy. There is a limited similarity here with environmental impact statements for large scale development.

Thus, large lending institutions, such as the World Bank, that are essentially funded by the developed nations should require a land-use plan and mine action plan as part of the loan process. The land-use plan should include the strategies discussed in this paper for improving the cost-effectiveness of land certification operations. The plan should include dual use of equipment, especially expensive equipment, so that demining is carried out in concert with infrastructure development with benefit to both activities. The selection of regions to develop should be made with a view to financing nearby clearance operations, as described in this paper.

\section{Financial Support}

The financial burden of mine action should be shared equitably. An equitable approach would account for the level of responsibility for the problem, the ability to provide resources for its solution, and a deterrent factor to discourage future actions that tend to exacerbate the problem. The problem is clearly not uniquely the responsibility of those who emplaced the mines, but is really a global responsibility involving mine producers, war materials suppliers, policymakers, and government agencies through- 
out the world. There is indeed a spectrum of moral responsibility for the condition that includes everyone, possibly encompassing even those whose only relevant actions have been to do nothing. Correlating the burden with the level of responsibility creates a measure of deterrence, if it can be enforced. There is a limited similarity here with the concept of moral hazard used by the insurance industry to encourage behavior that reduces the risk of loss. However, the burden on a particular country should clearly be tempered by its ability to provide funds and other resources. In this way, the burden should be proportionately greater for the developed nations, and for those with historically high levels of war material production and distribution to areas in civil conflict.

Economic analysis has shown that mineinfested countries simply cannot afford to solve the landmine problem on their own. It is likely that funds generated by purely humanitarian appeals for help will also fall well short. The community of nations must determine an equitable distribution of the burden and decide to make funding for demining an integral part of foreign policy and international agreement.

Using the new paradigm discussed in this paper, the scale of the worldwide effort is well within the resources of the developed world to provide. An international working group should be convened and tasked with creating a workable process of determining an equitable sharing of the burden and creating the necessary and appropriate international agreements.

\section{Technology Development}

Technology policy should include a greater emphasis on relevant technologies, with funding for technology development managed by individuals skilled and knowledgeable in the realities of local mine action. The near-term focus should be on multiplicative technologies, rather than advanced technologies.
In broad terms, the technologies of greatest impact are those that will determine that large areas of land are indeed free of mines, that will discriminate effectively against clutter, and that will improve the efficiency of current demining operations. Technologies for rapid, wide-area search with acceptable quality assurance would seem to be several years away, but there are combinations of current technologies and procedures-that could be implemented and deployed relatively quickly-that can have limited success in special circumstances. Technologies for clutter discrimination will involve the fusion of orthogonal sensors, as well as improvements in current detection methods. Technologies for incorporating efficient clutter rejection are several years away, but there are approaches using current sensor methods that might provide some advantage in limited circumstances in the near-term. Technologies for assisting current methods of demining operations may well exist, but a clear set of criteria is needed.

The most pressing need in technology development is a clear operations analysis of protocols and procedures of demining operations. A study group of scientists and engineers should be formed to take on this task. After suitable training and education in mine clearance methodology, this group should go on moderate-length field visits to areas where mines are being cleared, so that its members can study the process and make recommendations in regard to those functions and associated performance standards that would significantly improve the speed or reliability of field operations.

\section{Maps and Other Supporting Data}

Reliable maps of minefields, infrastructure, population, agriculture, industry, transport, and other data necessary to the development of a mine action section of a reconstruction plan, as well as the critical and at-present inadequately defined role for technology, are needed. A study group should be formed 
with the charter to examine constructs for international organization that would best use the resources and knowledge of the world for this purpose.

\section{Other Recommendations}

International development funds should also be used to support the training of managers who are fluent in current business practices to facilitate monitoring of in-country mine action and to ensure financial and operational accountability.

The military use of landmines should be re-examined with emphasis on enabling the clearing of minefields and rendering mines safe post-conflict.

Research on military tactics and strategies for responding to fast mine-clearing technologies adequate to support sustainable demining would reduce the incentive to use landmines, and hence their emplacement rate. A military study on the possible use of a ban on emplacement methods that are faster than that of a single soldier, to help mitigate the emplacement rate, would be useful.

Pressure is required to force combatants to make adequate plans for removing landmines and other UXO after the conflict is over. This pressure could take the form of economic measures, or legal measures based on the criminalization of the reckless use of landmines under international humanitarian law. Policy should include a careful analysis of the definition of a landmine from the point of view of enforceability. 
32 Landmine Policy in the Near-Term 
Appendix A: Conference on Technology Needs for Humanitarian Demining $\mid 33$

\section{Appendix A}

Conference on Technology Needs for Humanitarian Demining 


\title{
(Addendum : January 1998)
}

A conference was held in December 1997 on technologies for humanitarian demining, with emphasis on identifying the real problems that deminers face in the field. The conference agenda is reproduced here, together with a description of the major conclusions.

Host: $\quad$ Center for Global Security Research

Chair: $\quad$ David Eimerl, LLNL, CGSR

Co-Chair: Milt Finger, LLNL, DoD Programs

\section{AGENDA}

\author{
9:00 am Daniel Layton \\ "The 2010 Initiative" \\ 9:15 am Brigadier P. Blagdon \\ "Humanitarian Landmine Action Overview" \\ 10:00 am George Foscanaem \\ "The Mine Action Centre" \\ 11:00 am Bob Keeley, Handicap International \\ "On the Ground in the Minefield" \\ 1:15 pm Robert Leitch, George Washington University \\ "Treatment of Landmine Injuries" \\ 2:15 pm Carolyn Taylor, Mine Action Associates \\ "The International Market for Demining Technology" \\ 3:00 pm Jason Regnier, US Army, Ft. Belvoir \\ "DoD Technologies for Landmine Action" \\ 4:00 pm Milt Finger, LLNL, DoD Programs \\ "LLNL Technologies for Landmine Detection"
}




\title{
Technologies for Humanitarian Landmine Action
}

\author{
Dec 15th 1997
}

\section{Summary of Findings}

\section{(1) Problem Is New and Complex}

(a) Humanitarian landmine clearance is a comparatively new field. We (the international community) have never attempted to solve a problem like this on a worldwide scale before at any time in history. There is a lot to learn about the most effective way to clear mines.

(b) It is complex field, involving local politics, military security, economic development, advanced technology, and international stability.

(c) There is weak coordination between the active players in just about every aspect of international action.

\section{(2) Information Is Not Adequate}

(a) Information on methodology and logistics is generally based on the experience on in-the-field NGOs and MACs. It has not been organized into a generally accepted protocol, and it is not readily available.

(b) Information on mine clearance equipment and technologies has been closely held by defense establishments worldwide. In the last year or so, this is beginning to change.

(c) Information on minefields themselves is sporadic, at best. In some cases such information is regarded as protected military secrets.

(d) Information on the terrains and type of mines/UXO present is often not available. (This would be useful to prioritizing technology development efforts.) (e) Information necessary to planning is not available-demographics, refugees, agriculture, infrastructure, power and potable water, roads and transportation, means of production.

\section{(3) Local Politics Are Significant}

(a) Each region of the world presents unique operational challenges arising from uncertain policies from local regional authorities.

(b) In regions recovering from civil war, central organization is often weak or nonexistent. Subregions may be controlled by local authorities who remain somewhat independent of central government.

(c) Acquiring planning information may be infeasible or of low priority in regions where local security is the major concern.

\section{(4) Mine Clearance Can Be Divided into Four Steps}

(a) Level 1 survey: Wide area search to identify the general areas of contamination.

(b) Level 2 survey: Determination of the exact edges of mined areas in a contaminated region.

(c) Clearance: Removal and disposal, or render-safe of all mines within the mined area.

(d) Quality Assurance: Provide high degree of confidence that there are no mines left in the entire suspected area of contamination. 


\section{(5) Mined Areas Are Highly Varied}
(a) Open fields, light brush, heavy brush, dense vegetation.
(b) Hard/soft ground, wet/dry/muddy, rocky/sandy/loamy.
(c) Flat, sloping, steep.
(d) Weathered/ intermittent running water/rain.
(e) Buildings, detritus from bombed structures/vehicles/machinery.
(f) After being laid, minefields often become overgrown, particularly in humid, fecund climates.
(g) Aged mines are unpredictable.

\section{(6) Current Methods}

(a) Open Field Methods

(1) Trained dogs: Participate in Level 1 and 2 surveys and quality assurance.

(2) Flails: Level 2 surveys.

(3) Metal detectors: Level 2 surveys and mine removal.

(4) Prodders: Mine removal.

(5) Large Mechanical Machines: Terrain clearance for Level 2 survey and mine clearance. Mine detection on roads.

(b) Other Methods Reported, But Not Yet Accepted in the Field

(1) Airborne optical/IR/wideband for wide area Level 1 survey.

(2) Aboveground chemical sensors for Level 1 survey, Level 2 survey, removal and quality assurance.

(3) Ground-penetrating EM radiation: Radar imaging/detection for Level 2 surveys, mine removal and quality assurance.

(4) Ground-penetrating nuclear/Xrays : In-situ identification of explosives.

(5) Sensor fusion.

(c) Other Equipment Needed

(1) Practical protective gear.

(2) Medical assistance tools.

\section{(7) Demining Needs in Clearance Technologies}

(a) Background:

(1) There is no universally agreed protocol for mine clearance activities, that includes all aspects of the logistics from the decision to go into a region, to the point of departure from that region. This impedes estimating the value of potential future technologies.

(2) There is no universal clearance technology that performs all functions in all terrains.

(3) Some terrains have essentially no solution, e.g. buildings, dense foliage

(4) We do not have a complete set of effective technologies to cover all situations.

(b) Detection and Removal

(1) Wide area search.

(2) Rapid methods for confirming that a tract of land is not mined.

(3) Effective means of dealing with clutter.

(4) Methods for all terrains, especially buildings and denser foliage.

(5) Better protective gear

(6) Impartial test and evaluation of clearance technologies.

(7) Quality assurance technologies to confirm $100 \%$ effectiveness.

(c) Management Tools

(1) Design tools for better protective gear.

(2) Operational planning for optimizing use of resources.

(3) Tools for making trade-offs on capital items vs payoff.

(4) Better search strategies.

(5) Overall program planning and management.

(6) Rapid access to reliable data on suspected contaminated areas. 
(d) Training Tools

(1) Testing and certification for mine clearers.

(2) Training for medical emergency/first-aid teams.

(e) Support Functions

(1) Effective protection and logistics support for demining teams.

(2) Administrative support, incountry.

\section{(8) The Field Needs Definition}

(a) There is a pervasive sense of a lack of coherence at just about every level.

(b) There is a need for:

(1) better assessment of field protocols.

(2) a systems model for estimating the impact of new technology.

(3) a technically sound and impartial assessment of emerging technologies.

(4) collection and organization of the many worldwide technology development activities, usually within various defense establishments.

(5) a practical mechanism for accomplishing the collection and organization of the many worldwide technology development activities.

(6) better information on minefields.

\section{(9) Relation to Defense Needs}

(this was not discussed at the conference, but is added here for completeness)

(a) Defense needs alternatives to AP mines for war-fighting:

(1) Denial of unrestricted maneuvers.

(2) Delay to enhance other weapon systems' effectiveness.

(3) Provide alert and/or warning.

(4) Cause direct, non-lethal casualties.

(b) Methods for mine removal:

(1) Breaching.

(2) Countermine.

(3) Battlefield Clearance.

(4) Active Range Clearance.

(5) Counterterrorism.

(c) War-fighting needs are disjoint with humanitarian requirements:

(1) Primary responsibility is defense, not international action.

(2) Defense needs mil-spec equipment, humanitarian demining does not.

(3) Humanitarian demining is low intensity, not war-fighting speed.

(4) Defense does not need $100 \%$ effectiveness; humanitarian demining must be $100 \%$ effective.

(5) Humanitarian demining technologies are unlikely to be fast enough to be useful for warfighting.

(d) Peacekeeping operations and nonwar-fighting roles:

(1) PKOps are likely to increase in the future.

(2) PKOps may involve military personnel in training, information systems or other assistance for humanitarian demining, but not active mine clearance. 
38 Landmine Policy in the Near-Term 
Appendix B: Landmine Who's Who 39

\section{Appendix B}

\section{Landmine Who's Who}


Auburn University, Department of Bectrical Engineering 200 Broun Hall

Auburn University, AL 36849-5201, USA

Phone: (334) 844-1800; Fax: (334) 844-1809

Academic

Carnegie Mellon University, Field Robotics Center

5000 Forbes Avenue

Pittsburgh, PA 15213, USA

Phone: (412) 268-2000; Fax: (412) 268-5895

Academic

Various detection \& neutralization

http://www.cmu.edu/

Chalmers University of Technology

Department of Applied Eectronics

S-412 96 Göteborg, Sweden

Academic

Ground penetrating radar

http://www.ae.chalmers.se/

Colorado State University

Department of Eectrical Engineering

Fort Collins, CO80523, USA

Phone: (970) 491-1101

Academic

Cooperative Research Centre for

Sensor Signal and Information Processing

Warrendi Road, The Levels

SA 5095 Australia

Phone: (61) 83025021

Academic

Duke University

Department of Eectrical and Computer Engineering

Box 90291

Durham, NC27708, USA

Phone: (919) 660-5252; Fax: (919) 660-5293

Ground penetrating radar

http://www.duke.edu/

Ecole Polytechnique Fédérale de Lausanne ( $\mathrm{PR}$ )

Laboratoire de Microinformatique (LAMI)

IN-FEcublens, CH-1015 Lausanne, Switzerland

Phone: (41) 21693 2641; Fax: (41) 216935263

Academic

Georgia Institute of Technology

School of Eectrical \& Computer Engineering

Atlanta, GA 30332-0250, USA

Phone: (404) 894-2900; Fax: (404) 894-4641

Academic

Ground penetrating radar

http://www.ece.gatech.edu/ http://diwww.epfl.ch/lami/

detec/detec.html 


\section{Organizartion}

lowa State University

Snedecor Hall

Ames, IA 50011, USA

Phone: (515) 294-3440; Fax (515) 294-4040

James Madison University

Humanitarian Demining Information Center

University Blvd - Stop 4003

Harrisonburg, VA 22807, USA

Phone: (540) 568-2718; Fax: (540) 568-2747

Academic

Pattern recognition

http://www.iastate.edu/

King's College London

Chemistry Department

Strand, London, WC2R 2LS, UK

Phone: 44171873 2358; Fax: 441718732810

Academic

McMaster University, Centre for International Health

Hamilton, Ontario, L8N 3Z5, Canada

Phone: (905) 525-9140 ext. 22035; Fax: (905) 525-1445

Academic

Monash University, Physics Department

Cayton 3168, Victoria, Australia

Phone: (03) 905 3595, Fax: (03) 9053637

Academic

National Center for Physical Acoustics

University of Mississippi

University, MS 38677, USA

Phone: (601) 232-5404

Academic

New Mexico Institute of Mining \& Technology

801 Leroy Place

Socorro, New Mexico 87801, USA

1320 Kinnear Rd.

Columbus, OH 43210, USA

Phone: (614)292-7981; Fax: (614)292-7297

Academic

Academic

- $\quad$ Feld testing countermine equipment

http://www.nmt.edu/

http://sunset.backbone.olemiss.

edu/depts/ncpal

http://crac3.ch.kcl.ac.uk

kclchem/

http://www.mcmaster.ca

http://www.monash.edu.au/

- Acoustic impulse detection

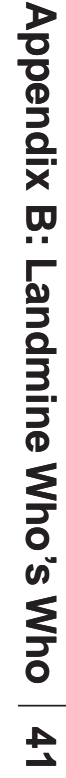

D=Demining

F=Finance

$\mathrm{H}=$ Humanitarian

P=Political

$\mathrm{R}=$ Research

http://www.acs.ohio-state.edu/ 
Royal Military Academy of Belgium

Avenue de la Renaissance 30

1000 Brussels, Belgium

Phone: (32) 27376111

Academic

- Microwave neutralization

http://www.rma.ac.be

Stanford University, Department of Eectrical Engineering

122 Godzilla Modular

340 Panama Street

Stanford, CA 94305-9505, USA

Phone: (650) 723-3931

Academic

University of Alabama in Huntsville

301 Sparkman Drive

Huntsville, Alabama 35899, USA

Phone: (205) 890-6000

Academic

University of Alberta, Department of Mechanical Engineering

Edmonton, Alberta T6G2G8, Canada

Phone: (403) 492-7031; Fax: (403) 492-2200

Academic

University of Auckland

Private Bag 92019

Auckland, New Zealand

Phone: +64 (9) 373-7999: Fax: +64 (9) 373-7400

Academic

University of Bristol

Bristol BS8 ITH, UK

Phone: 44 (0) 1179289000 Fax: 44 (0) 1179292396

Academic

University of Cape Town

Department of Bectrical Engineering

University Private Bag

Rondebosch 7701, South Africa

Phone: +27 (0) 21650 2799; Fax: +27 (0) 216503465

Academic

Ground penetrating radar

http://rrsg.e.uct.ac.za/ alan minerad.htm

University of Aorida

Department of Nuclear \& Radiological Engineering

P.O. Box 118300

Gainesville, Horida 32611-8300, USA

Phone: (352) 392-1401; Fax: (352) 392-3380

Academic

X-ray

http://www.nuceng.ufl.edu/

F=Finance $\quad$ H=Humanitarian


University of Kansas, Radar Systems \& Remote Sensing Lab 2291 Irving Hill Road

Lawrence, Kansas 66045, USA

Phone: (785) 864-7735; Fax: (785) 864-7789

Academic

University of Missouri-Columbia

Columbia, MO65211, USA

Phone: (573) 882-4523

Academic

University of Missouri-Rolla Intelligent Systems Center

1870 Miner Orcle

Rolla, MO65409-1060, USA

Phone: (573) 341-4111

University of Nebraska-Lincoln

Department of Bectrical Engineering

209N Walter Scott Engineering Center

P.O. Box 880511

Lincoln, NE68588-0511, USA

Phone: (402)472-3771; Fax: (402)472-4732

Academic

University of Queensland

Department of Eectrical and Computer Engineering

St Lucia, Queensland 4072, Australia

Phone: 6173365 3984; Fax: 61733654999

Academic

University of Texas at Arlington

Wave Scattering Research Center

Arlington, TX 76019-0016, USA

Phone: (817) 273-3422

Academic

University of Warwick, Department of Engineering,

Development Technology Unit

Coventry, CV4 7AL, UK

Phone: 44 (0)1203-523122; Fax: +44 (0)1203-418922

Academic

University of Western Australia

Nedlands, Perth, Western Australia 6907, Australia

Phone: +61 9380 3838; Fax: +61 93801380

Academic

Academic
Ground penetrating radar

http://www.rsl.ukans.edu/

- Various detection \& neutralization $\quad$ http://www.missouri.edu/

- Various detection \& neutralization

http://www.isc.umr.edu/

(1)

http://www.engr.unl.edu/ee/

- Ground penetrating radar

http://www.elec.uq.edu.au/

- Various detection \& neutralization

http://www-eng.uta.edu/

ttp://www.eng.warwick.ac.uk/

DTU/mines.html

Demining equipment

Manual demining, robotics

http://www.uwa.edu.au/ 


\section{Organization}

University of Wollongong

NSW 2522, Australia

Phone: +61-2-42213555

Type

$\mathbf{P} \mathbf{R}$

Research Interest

URL

University of Zagreb

Faculty of Eectrical Engineering and Computing

Unska 3, 10000 Zagreb, Croatia

Phone: +385 1 6129999, Fax: +385 16170007

Academic

Mechanical detection

http://www.uow.edu.au/

Western Kentucky University, Applied Physics Institute

Bowling Green, Kentucky, 42101, USA

Phone: (502) 745-5277, Fax: (502) 745-5062

Applied Bectromagnetics Ltd.

11 Bell Street

St. Andrews, KY16 9UR, UK

Phone: 01334477598

Commercial

BACTEC International Ltd.

Alpha House V.,Laser Quay

Culpeper Clo. Rochester ME2 4HU, UK

Phone: 441634296757 Fax: 441634296779

Academic

Neutron analysis

http://www.wku.edu/

Barringer Technologies

219 South Street

Murray Hill, NJ 07974, USA

Phone: (908) 665-8200

Biopraxis, Inc.

POBox 910078, 10655 Sorrento Valley Rd., Suite 20

San Diego, CA 92191, USA

Phone: (619) 452-2413

Biosensor Applications Sweden AB

Skäpplandsgatan 1

SE-703 46 Örebro, Sweden

Phone: +46 192611 00; Fax: +4619261101_Commercial

Bodenseewerk Geratetechnik GmbH

Germany

Commercial

H=Humanitarian

Ground penetrating radar

- Demining

- Ion mobility spectrometry

- Biosensor

- Biosensors

http:/mww.ny-industri.se abtsid1.htm 


\section{Organizartion}

Type

Bombs Away, Inc

388 South Marine Drive, \#102-117

Tamuning, Guam 96911, USA

Phone/Fax: (671) 789-7887

Commercial

http://www.bombsaway.net/

Charles Stark Draper Laboratory, Inc

555 Technology Square

Cambridge, MA 02139-3563, USA

Phone: (617) 258-1000; Fax: (617) 258-3050

Commercial

Unmanned undersea vehicles

http://www.draper.com/

Cearway Explosive Services Ltd.

Willowbank House, Willowbank Road,

Aberdeen AB1 2YG UK

Phone: 441224 586048; Fax: 441224581472

Commercial

CMS International Environmental Remediation Group

4904 Esenhower Blvd, Suite 310

Tampa, RL 33634, USA

Phone: (813) 882-0148; Fax: (813) 882-0396

Commercial

Coleman Research Corporation

201 South Orange Avenue, Suite 1300

Orlando, Horida 32801, USA

Phone: (407) 244-3700

Commercial

- Integrated detector - GPR and magnetic http://www.crc.com/

Computing Devices Canada

3785 Richmond Road

Nepean, Ontario, K2H5B7, Canada

Phone: (613) 596-7000; Fax: (613) 820-5081

http://www.computingdevices.com/

Commercia

Concept Engineering Group, Inc.

610 William Pitt Way

Pittsburgh, PA 15238, USA

Phone: (412) 826-3191

Commercial

Demining equipment

Oybernet Systems Corp.

1919 Green Rd. Suite B-101

Ann Arbor, Ml 48105, USA

Phone: (313) 669-2567; Fax: (313) 668-8780

Commercial

- Robotics

http://www.cybernet.com/ 


\section{Organization}

Daimler-Benz AG Research Center

Wilhelm-Runge-Strasse 11

89013 Ulm, Germany

Type

De-Mining International Ltd. (DMI)

The Nightingale Centre, 8 Balham Hill

London SW12 9EA, UK

Phone: 44(0)181 675 7077; Fax 44(0)181 6757277

Commercial

- Ground penetrating radar

http://www.daimler-benz.com/

Dynetics, Inc

1000 Explorer Blvd.

Huntsville, AL 35806, USA

Phone: (205) 922-9230; Fax: (205) 922-9255

Ground penetrating radar

(a)

http://www.heartlandsuk.com

\section{BMRAD Ltd.}

Langham Park, Catteshall Lane,

Godalming, Surrey, GU7 1NG, UK

Phone: 44 (0) 1483418 600; Fax: 44 (0) 1483418618

Commercial

Environmental Chemical Corp, UXODivision

12470 W. Cedar Drive

Lakewood, 00 80228, USA

Phone: (303) 989-8344; Fax: (303) 989-3530

EOD World Services, Inc.

P.O. Box 355

Fort Walton Beach, R 32549-0355, USA

Phone: (904) 664-0616; Fax: (904) 664-5650

\section{Commercial}

- Sensor fusion

巴RA Technology

Cleeve Road

Leatherhead

Surrey KT22 7SA, UK

Phone: 441372 367000; Fax: 441372367099

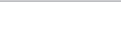

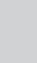

Commercial

- Ground penetrating radar

http://www.emrad.com/

Commercial

Exploration Logistics Ltd.

Rank Xerox Business Park

Mitcheldean Goucestershire, GL17 0DD, UK

Phone: 441594 544733; Fax: 441594544722

(n)

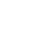

$\frac{\frac{1}{7}}{3}$

Commercial

Commercial

- Ground penetrating radar

http://www.era.co.uk

Commercial 


\section{Organizartion}

Fellows International Ltd.

P.O. Box 1227 Arundel,

West Sussex BN18 0AU, UK

Phone: 441243 551025; Fax 441243555740

Foerster UK Ltd.

Unit 9, Wrens Court, 50 Victoria Road

Sutton Coldfield, West Midlands B72 1SY, UK

Phone: 0121321 1166; Fax: 01213211066

GDE Systems, Inc.

P.O. Box 85468

San Diego, CA 92186-5468, USA

Phone: (619) 592-5567

Geosoft Inc.

85 Richmond St. W.

8th Hoor, Toronto, ON, M5H2C9, Canada

Phone: (416) 369-0111; Fax (416) 369-9599

Gerbera $\mathrm{GmbH}$

Bahnhofstrasse 4

15711 Koenigs Wusterhausen, Germany

Phone/Fax: 493375290721

GTECConsult $\mathrm{GmbH}$

Bongardgasse 3

D-40479 Düsseldorf, Germany

Phone: 49 211-4408 0; Fax: 49 211-4408 204

Golden West International

15233 Ventura Blvd, Penthouse 8

Sherman Oaks, CA 91403, USA

Phone: (818) 981-6400; Fax: (818) 501-6181

Greenfield Consultants

The Nightingale Centre, 8 Balham Hill

London SW12 9EA, UK

Phone: 44(0)181 6757077

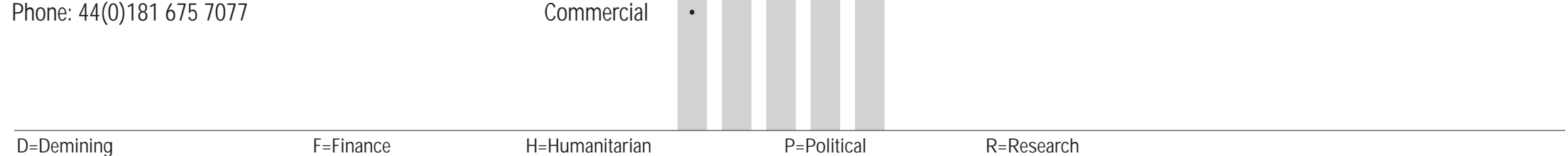

http://muwfellows-int com/

http://www.foerstergroup.com/

Integrated detector - GPR and magnetic http://www.gdesystems.com/

Image processing

http://www.geosoft.com 


\section{Organization}

Guartel Limited

16 Alliance Court

Aliance Road

ondon W3 0RB, UK

Phone: 44(0)181 896 0222; Fax: 44(0)181 8960333

Heartlands Group, Ltd.

Swansley Wood, A428

Caxton, Cambridgeshire, CB38PH, UK

Phone: 44+1954718408; Fax: 44+ 1954718134

Type

IBM Corporation

Zp 1530, 905/3D-019

Austin, TX 78758-3493, USA

Commercial

IDAS - International Danger \& Disaster Assistance

Breestraat 161-163; 1941 日 Beverwijk, Netherlands

Phone: 31251 220253; Fax: 31413350747

Commercial

- Metal detectors

http://www.guartel.com

Interim Mekong Committee

C/OEscap UN Building, Sala Santitham

Rajddamnern Avenue, Bankok 10200, Thailand

Commercial

- Demining equipment

http://www.heartlandsuk.com.

Commercial

\section{International Demining}

927 Church Street

Pretoria, 0083, South Africa

Phone/ Fax: 27(0) 12433458

Commercial

ITRES Research Limited

\#155, 2635 37th Avenue NE

Calgary, Alberta T1Y 5Z6, Canada

Commercial

IUT - Institut für Umwelttechnologien $\mathrm{GmbH}$

Rudower Chaussee 5

12484 Berlin, Germany

Phone: 63925511

Commercial

- $\quad$ Neural networks

http://www.ibm.com/

Jaycor

9775 Towne Centre Drive

San Diego, CA 92121, USA

Phone: (619) 453-6580

Commercial

H=Humanitarian http://www.uia.org/uiademo/ org/e4160.htm

http://www.satern.com/ID

- Multispectral remote sensing

http://www.itres.com/

- Neutron backscatter \& metal detection

$\mathrm{R}=$ Research
F=Finance

$\mathrm{H}=$ Humanitarian 


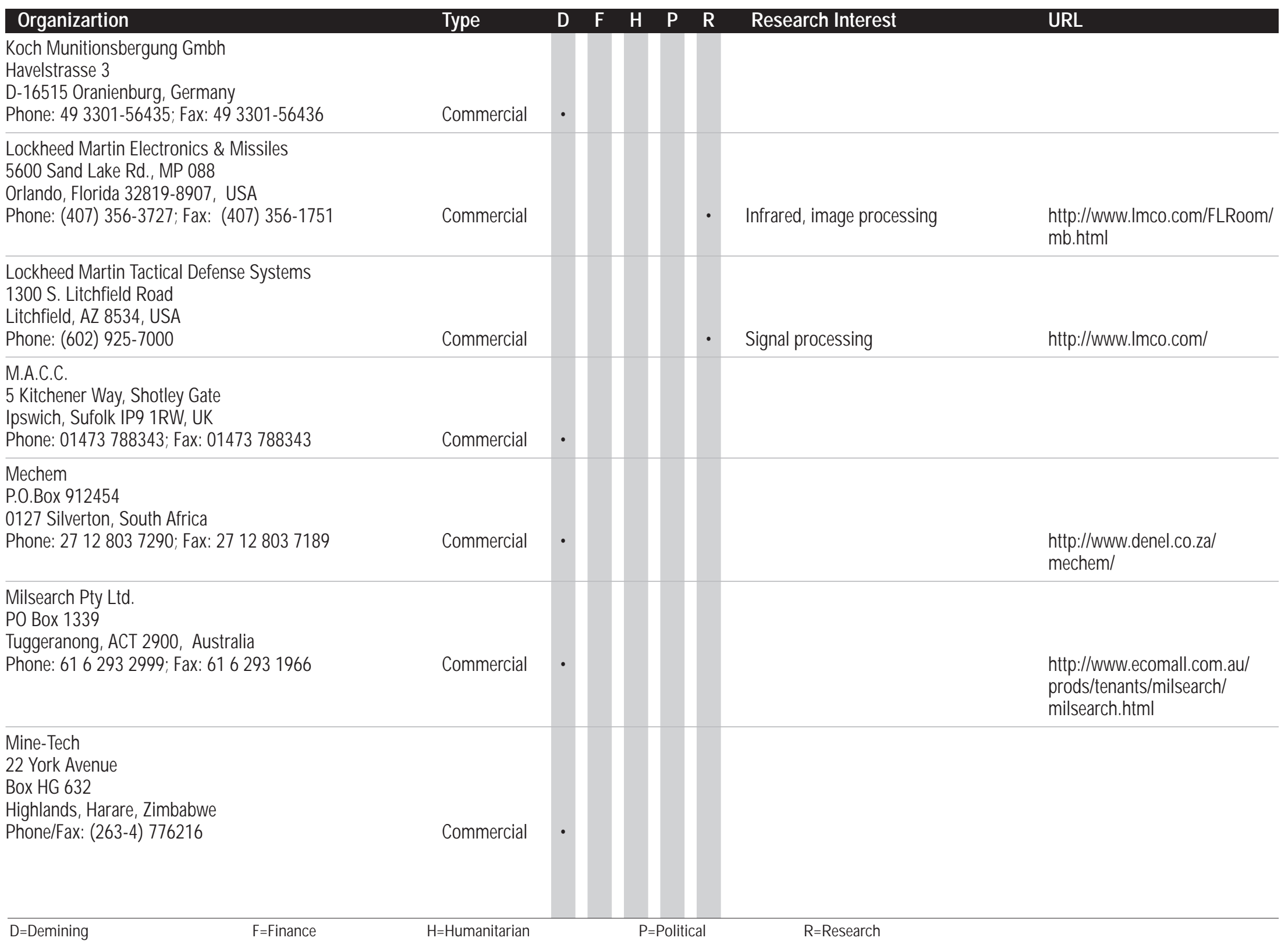


Mitre Corporation

1820 Dolley Madison Boulevard

McLean, VA 22102-3481, USA

Phone: (703) 883-6000

Commercial

- Ground penetrating radar

http://www.mitre.org/

Nichols Research Corporation

4040 South Memorial Parkway

Huntsville, AL 35802, USA

Phone: (205)883-1170

Commercial

IR detection

http://www.nichols.com

OAOCorporation/Robotics Division

9639 Doctor Perry Road, Space 209S

ljamsville, MD 21754, USA

Phone: (301) 874-2205; Fax: (301) 874-2199

Commercial

- Robotics

http://www.oao.com/robotics/

PL BRAKE

Krogebjerg 6

DK-2720 Vanloese, Denmark

Phone: 453879 2767; Fax: 4538792787

Commercial

Detection and demining equipment

http://www.pl-brake.com

Quantum Magnetics, Inc.

San Diego, CA, USA

Phone: (619) 566-9200

Commercial

Raton Technology Research

1030 Clayton $\mathrm{Rd}$

Raton, NM 87740, USA

Phone: (505) 445-3607

Commercial

Raytheon Bectronic Systems

Air \& Strike Systems

180 Hartwell Road

Bedford, MA 01730, USA

Commercial

Ribbands Explosives Ltd

COTEC, Gore Oross, West Levington

Wilts, SN10 4NA, UK

Phone: 441380812400

Commercial

RONCO Consulting Corporation

2301 M Street, NW, Suite 400

Washington DC20037, USA

Phone: (202) 785-2791 Fax: (202) 785-2078

Commercial

- Various

D=Demining

F=Fnance

$\mathrm{H}=$ Humanitarian

P=Political

R=Research

- Ground penetrating radar

- Airborne detection

http://www.raytheon.com/res/

http://www.ribbands.co.uk/

http://www.demining.com/ 


\section{Organizartion}

Royal Ordnance, Explosive Ordnance Disposal

Euxton Lane

Chorley, Lancashire PR7 6AD, UK

Phone: 441257 265511; Fax: 441257242555

Sagem SA

27, rue Leblanc

75512 Paris Cedex 15, France

Phone: 01407063 43; Fax : 0140706743

Type

Sanders, a Lockheed Martin Company

NHQ1-765, POBox 868

Nashua, NH 03061-0868, USA

Commercial

Satimo

ePin

Rue de la Terre de Feu

ZA de Courtaboeuf

91952 Les Ulis Cedex, France

Phone: 331692902 47; Fax: 33169290227

Schiebel Technology, Inc.

2127 California Street, NW, Suite 804

Washington, DC 20008, USA

Phone: (202) 483-8311; Fax: (202) 483-8316

Commercial

Science Applications International Corporation

2950 Patrick Henry Drive

Santa Clara CA 95054 USA

Phone: (408) 727-0607; Fax: (408) 727-8748

Search Training International Ltd.

Office 3, Courtlands Farm

Turnden Lane, Oranbrook TN17 2QL, UK

Phone: 01580715038

\section{Sensoria}

99 Spring Street, Suite K

Cambridge, MA 02141, USA

Phone: (617) 576-6231

Commercial

- Vapor detection http://www.sanders.com/

http://www.saic.com/ 



\section{Organizartion}

Aeronautical and Maritime Research Laboratory

Weapons Systems Div. Defence Science and Technology Org.

POBox 4331

Melbourne, Victoria 3001, Australia

Phone: (03) 96268539.

Government

CSIRODivision of Telecommunications and Industrial Physics

Bradfield Road, West Lindfield

POBox 218 Linfield, NSW 2070, Australia

Phone: (02) 9413 7569; Fax: (02) 94137202

Government

Defence Research Establishment Suffield

Box 4000

Medicine Hat, Alberta, T1A 8K6, Canada

Government

Defence Science and Technology Organization

Microwave Radar Division

POBox 1500

Salisbury, South Australia 5108, Australia

Phone: (08) 259 6851; Fax: (08) 2596673

Department of Small Arms, Special Equipment and Security

Ministry of Interior

Savska cesta 31, HR-10000 Zagreb, Oroatia

Phone: (+385 1) 612 2413; Fax (+385 1) $511263 \quad$ Government

\section{European Commission Joint Research Center}

Space Applications Institute

Via E Fermi

P.O. Box TP 440/112

I-21020 ISPRA(VA), Italy

Phone: +39 332 789298; Fax: +39 332789536

Institut National de Recherche en Informatique et en Automatique

Sophia Antipolis

2004 route des Lucioles - B.P. 93

06902 Sophia Antipolis Cedex, France

Phone: 334936577 771; Fax: 33493657765

Government
Countermine; acoustic imaging

http://www.dsto.defence.gov.au/

http://www.tip.csiro.au/

Detection

http://www.dres.dnd.ca/

Ground penetrating radar

Mechanical probe

http://www.rasip.fer.hr/ d mine_project.html

http://www.jrc.it/sai/ http://www.inriafr/ 


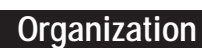

Type

Jet Propulsion Laboratory

4800 Oak Grove Drive

Pasadena, California 91109, USA

Phone: (818)354-4321

Government

Lawrence Livermore National Laboratory

7000 East Ave., P.O. Box 808

Livermore, CA 94550, USA

Phone: (510) 422-1100

Government

Los Alamos National Laboratory

P.O. Box 1663

Los Alamos, NM 87545, USA

Phone: (505) 667-5061

Government

Ministry of Defence

The Minister's Correspondence Unit

Room 6140, Main Building

Whitehall, London SW1A2HB, UK

Phone: 0171-218 6645

Government

National Defence Research Establishment - FOA

Department of Radar Systems, FOA 36

P.O. Box 1165

S-581 11 Linköping, Sweden

Government

Naval Postgraduate School

1 University Circle

Monterey, CA 93943-5001, USA

Government

Naval Research Laboratory

Chemical Dynamics \& Diagnostics Branch

Code 6110 Washington, DC20375, USA

Phone: (202) 767-3340

Government

Newcastle General Hospital, Regional Medical Physics Dept.

Westgate Road

NE4 6BENewcastle-Upon-Tyne, UK

Phone: 0191273 8811; Fax: 01912260970

Government

- Various

http://www.jpl.nasa.gov/

(1)

http://www.Ilnl.gov/

http://www.lanl.gov/

http://www.mod.uk

http://www.foase/

http://www.nps.navy.mil/

http://www.nrl.navy.mil/ 


\section{Organizartion}

Oak Ridge National Laboratory, Advanced Methods Group

P.O. Box 2008, Building 3546, MS 6011

Oak Ridge, Tennessee 37831-6011, USA

Phone: (423) 574-5278; Fax: (423) 574-6663

Office National d'Éudes et de Recherches Aérospatiales

Centre d'Etudes et de Recherches de Toulouse

BP 4025 - 2, avenue Edouard Belin

31055 Toulouse Cedex France

Phone: 33 (0) 5.62.25.25.25

Fax : 33 (0) 5.62.25.25.50

vivernment

Sandia National Laboratories, New Mexico

POBox 5800

Albuquerque, NM 87185, USA

Government

Senator Patrick Leahy

433 Russell Senate Office Building

United States Senate

Washington, D.C. 20510, USA

Phone: (202) 224-4242

US Army Cold Regions Research and Engineering Laboratory

72 Lyme Road

Hanover, New Hampshire 03755, USA

Phone: (603) 646-4100

Government

S Army Communications \& Bectronics Command

Night Vision \& Eectronic Sensors Dir. Countermine Div.

10221 Burbeck Road, Suite 430

Fort Belvoir, VA22060 - 5806, USA

Government

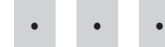

US Army Materiel Command

Alexandria, VA, USA

Government

US Army National Ground Intelligence Center

220 Seventh Street, NE

Charlottesville, VA 22902-5396, USA

Government

Ground penetrating radar http://amc.citi.net/

- Problem definition itt//mww.monmouth.army.mil/

cecom/rdec/rdec.htm

http://www.crrel.usace.army.mil/

http://www.senate.gov/ leahy/ landmine.htm

http://www.ornl.gov

http://www.cert.fr/

http://www.sandia.gov/ 
US Army Research Laboratory

Adelphi Laboratory Center

2800 Powder Mill Road

Adelphi, MD 20783-1197, USA

Government

- Radars

http://www.arl.mil/

US Army Tank-Automotive Research,

Development and Engineering Center

Detroit Arsenal

Warren, Ml 48397-5000, USA

Phone: (810)574-5663; Fax: (810) 574-5097

Government

US Department of Defense, UXOCenter of Excellence

Attn: AMSE-RD-UXO-CO

10221 Burbeck Rd.

F. Belvoir, VA22060-5806, USA

Fax: (703) 504-2074

/

US Naval Explosive Ordnance Disposal Technology Center

2008 Stump Neck Road

Indian Head, MD 20640-5070 USA

Phone: (301) 743-6850; Fax: (301) 743-6927

Government

Government

http://uww.denix.osd.mil/UXOOOE

US State Department, Bureau of Political-Military Affairs

Washington, DC20520, USA

Phone: (202) 647-0094; Fax: (202) 647-2951

Government

European Union

Rue de la Loi 200, B-1049 Brussels, Belgium

Phone: 3222991111

International

Robotics

http://www.tacom.army.mil/tardec/

UN Department of Humanitarian Affairs

Mine Clearance and Policy Unit

United Nations, S-3600, New York, NY 10017, USA

Phone: (212) 963-4635; Fax: (212) 963-1312

International

-.

http://www.un.org/Depts/Landmine/

UN Department of Peace-Keeping Operations

Demining Unit

United Nations, U-510, New York, NY 10017, USA

Phone: (212) 963-1875; Fax: (212) 963-3452

International

- Robotics

http://www.state.gov/unw/ global/arms/

http://158.169.50.70/index-en.htm 


\section{Organizartion}

Type

D

H

$\mathbf{P}$

UNICE

3 United Nations Plaza

New York, New York 10017, USA

Phone: (212) 326-7000; Fax: (212) 888-7465

International

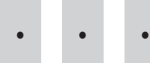

http://www.unicef.org/

World Bank Group

1818 H Street, N.W.

Washington, D.C. 20433, USA

Phone: (202) 477-1234; Fax: (202) 477-6391

International

http://www.worldbank.org/

Action Solidarite Tiers Monde

rue du Fort Neipperg, 39

2230 Luxembourg, Luxembourg

Phone: 352/400/427; Fax: 352/40.58.49

NGO

Afghan Campaign to Ban Landmines

House No. 13, Street 19

F-8/2, Islamabad, Pakistan

Phone: 92-51-855-939 Fax: 92-51-282-617

NGO

Australia Network

GPOBox 2602, Adelaide SA 5001, Australia

Phone: 61-8-210-8172; Fax: 61-8-231-5175

Ban Landmines/Nepal

Women Development Society

GPO5840

Katmandu, Nepal

Phone: 977-1-271-794; Fax: 977-1-270-396

BOCS Foundation

H-8003 Szekesfehervar, Pf. 7 Hungary

Phone: 36-22-327-263

.

Cambodia Campaign to Ban Landmines

NGOForum on Cambodia, POBox 2295

Phnom Penh Cambodia

Phone: 855-23-60-199

NGO

-

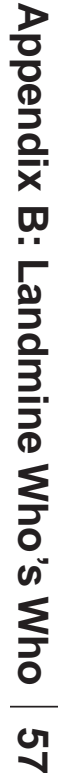

http://www.murchie.com/pig mines.html http://www.c3.hu/ bocs/ 
Organization

CAMEO Security

1009 Oak Orescent

cornwall, Ontario K6J 2N2, Canada

Phone: (613) 936-6815; Fax: (613) 936-6635

Campaign Against Landmines (CALM)

6 John Sims Drive

Broadmeadows, Wellington 6004, NZ

Phone: 64-4-385-4874; Fax: 64-4-384-2112

Type

NGO

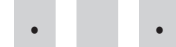

http://www.cameo.org/

Canadian International Demining Centre (CIDC)

P.O. Box 86

Sydney, Nova Scotia B1P 6G9, Canada

Phone: (902)862-8911; Fax: (902)862-7354

NGO

NGO

$\bullet$

CARE

151 日lis Street NE

Atlanta, GA 30303-2439, USA

Phone: (800) 521-CARE, ext. 999

NGO

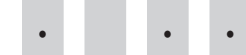

http://www.protel.co.nz/calm/

$\mathrm{CHHR}$

POBox 2340

Lilongwe, Malawi

Phone: 265741 292; Fax: 265741292

CMAC-Cambodian Mine Action Center

Building \#22, Road 122, Quarter Mittaheap

PO.Box 116

District 7 January, Pnom Penh, Cambodia

Phone: (855) 23-360096; Fax: (855) 23-426270

NGO

CMCM

c/o PDC

Av Eduardo Mondlane, 1170 r/c

Maputo, Mozambique

Phone: 2581430 430/1; Fax: 2581422595

NGO

DanChurchAid

Norregade 13

1165 Kobenhavn K, Denmark

Phone: +45-33-15-28-00; Fax: +45-33-15-38-60

NGO

http://inet.uni-c.dk/ rdcadk/home.htm 
00520 Helsinki, Fnland

Phone: +358-0-141; Fax: +358-147-297

NGO

Gaston Z Ortigas Peace Institute

Social Development Complez

Ateneo de Manila University

Loyola Heights, Quezon City, Philippines

Phone: +632-924-4557

Green Earth Organization

POBox 16641

Accra - North, Ghana

Phone: +23321 230 455; Fax +233 21232762

HALOTrust

804 Drake House

Dolphin Square

London SW1V 3NW, UK

Phone: 44171821 9244; Fax: 441718340198

NGO

Handicap International

14, Avenue Berthelot

F-69007 Lyon Cedex 07, France

Phone: 337869 7979; Fax: 3378697994

GO

http://www.handicap-

Human Rights Watch Arms Project

1522 K Street NW

Washington, DC20005 USA

Phone: (202) 371-6592; Fax: (202) 371-0124

IPMSA-SOORP

19 Saleh Ali

Gianlies, Alexandria, Egypt

Phone: +20-3-5718-165; Fax: +20-33-541-0297

international.org/

http://www.hrw.org

http://www.ifmsa.org/scorp/ 


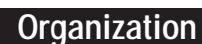

Indian Institute for Peace, Disarmament \&

Type

Environmental Protection

537 Sakkardara Road

Nagpur 440 009, India

Phone: +91-712-745-806; Fax: +91-712-722-337

NGO

Institut fuer Kommunikation und Medien

Kaulbachstrasse 22

D-80539 Muenchen, Germany

Phone: +49-89-2386-2400; Fax: +49-89-2386-2402

International Committee of the Red Cross

19, Avenue de la Paix

CH-1202 Geneva, Switzerland

Phone: 22 734-601; Fax: 22 733-2057

International Federation of Reconciliation/Austrian Branch

Ledererg. 23/3/27

A-1080 Vienna, Austria

Phone: 43-1-408-53-32

NGO

International Rescue Committee Inc.

286 Park Avenue South

New York, NY 10016, USA

Phone: (212) 679-0010; Fax: (212) 551-3180

JRS

Place de la Marie

$\mathrm{CH}-1256$ Troninex, Geneve, Switzerland

Phone: + 784 3084; Fax: + 3423327

JRS Malta

29, Marquis Scicluna Street

Naxxar NXR 03, Malta

JRS Spain

Roger de Lluria, 13

E08010 Barcelona, Spain

Phone: +34-3-301-2350; Fax: +34-3-317-8704

GO

$\cdot$

http://www.intrescom.org/

http://www.icrc.org

http://www.jesuit.org/refugee

http://www.jesuit.org/refugee

http://www.jesuit.org/refugee 
POBox 448

10760 Penang, Malaysia

Fax: 6046563990

Kenya Coalition Against Landmines

Maendeleo Ya Wanawake Organization

People for Peace in Africa

POBox 44412

Nairobi, Kenya

Phone: 254244 1372; Fax: 2542222095

Landmine Survivors Network

700 13th St. NW, Suite 950

Washington, DC20005, USA

Phone: (202) 661-3537; Fax: (202) 661-3529

Lutheran World Relief

390 Park Avenue South

New York, NY 10016 USA

Phone: (212) 532-6350; Fax: (212) 213-6081

http://www.lwr.org/

MAG

Rua Dak Doy 19D

Bairro Azul

Luanda, Angola

Phone: +244 2351505

Manitese

viale Somalia 28

00199 Rome, Italy

Phone: +39-6-8620-2756; Fax: +39-6-8620-2709

http://uww.citinv.it/associazioni/ manitese/

Médecins Sans Frontières - Doctors Without Borders

11 E, 26th Street, Ste. 1904

New York, NY 10010, USA

Phone: (212) 679 6800; Fax: (212) 6797016

NGO

http://www.msf.org/ 
MEDICOInternation

NGO

http://home.t-online.de/home/

D-60314 Frankfurt am Main, Germany

Phone: 4969 944380; Fax: 4969436002

\section{Mennonite Central Committee}

21 South 12th St., P. O. Box 500

Akron, PA 17501-0500, USA

Phone: (717) 859-1151

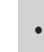

Mine Clearance Planning Agency - MCPA

House No.13, Street 19

F8/2, Islamabad, Pakistan

Phone:(+92)51 254292; Fax : (+92) 51282617

Mine Warfare Association

POBox 185

Newington, VA22122-0185, USA

Mines Action Canada

208-145 Spruce St.

Otawa ON K1R 6P1, Canada

Phone: +613-233-1982; Fax: +613-233-9028

NGO

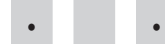

$\cdot$

$\bullet$

http://www.minwara.org/ medico.de

http://uww.mennonitecc.ca/mcd

Mines Advisory Group - MAG

54A Main Street,

Cockermouth, Oumbria CA13 9LU, UK

Phone: 441900 828580; Fax: 441900827088

NGO Committee on Disarmament

777 United Nations Plaza \#3B

New York, NY 10017, USA

Phone (212) 687-5340; Fax (212) 687-1643

NGO

NGOLandmines Group

Vietnam Veterans of America Foundation

9 Cao Ba Quat

Hanoi, Vietnam

Phone: +844-843-7348; Fax: +844-843-7574

NGO

D=Demining

F=Finance

H=Humanitarian

P=Political

$\mathrm{R}=$ Research

http://www.pgs.ca/pages/

Idmn0.html

http://www.mag.org.uk/

http://www.igc.apc.org/disarm/ 


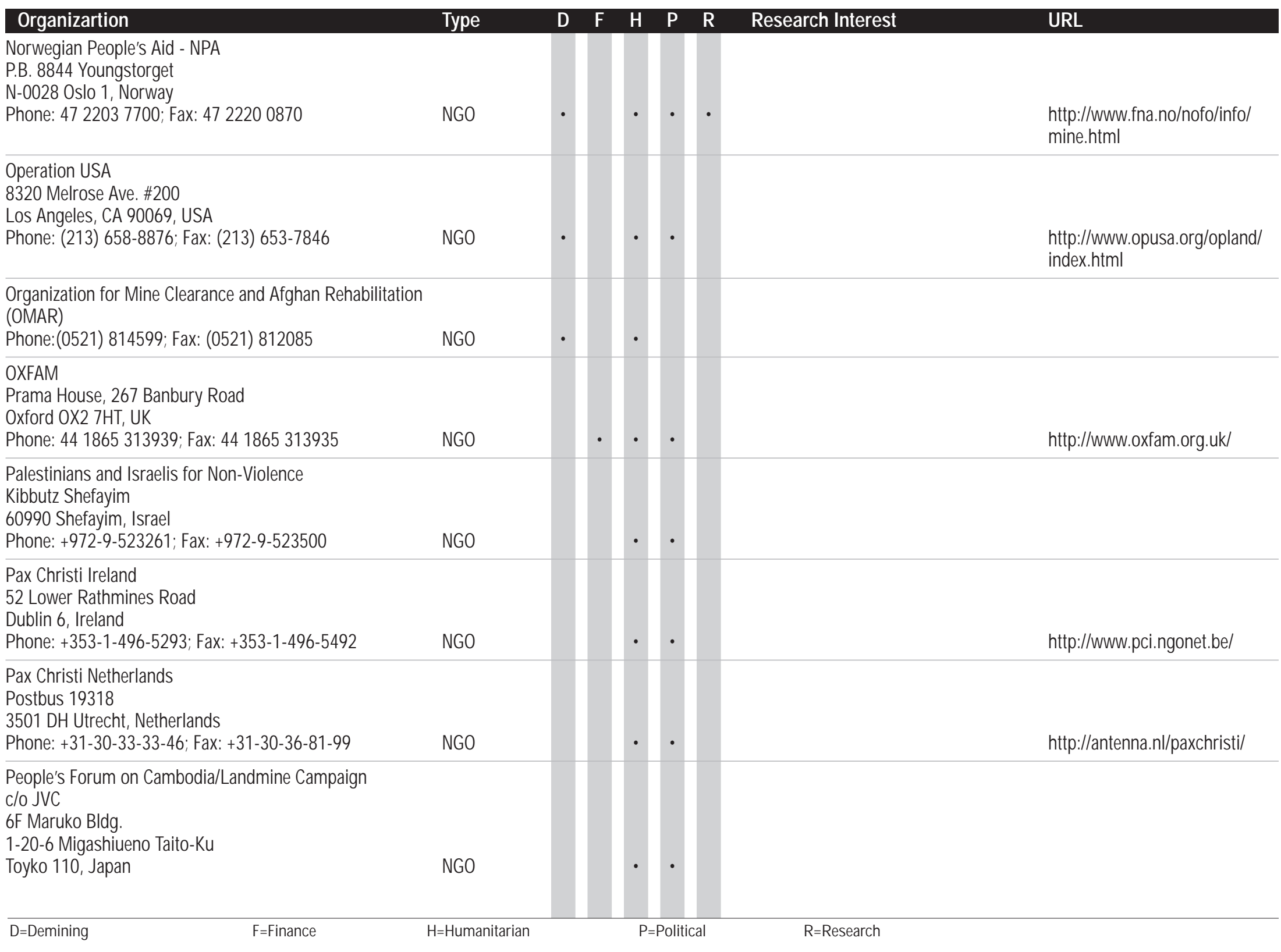




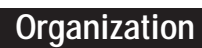

Type

Physicians for Gobal Survival, Canada

145 Spruce Street \#208

Ottawa, Ontario K1R6P1, Canada

NGO

Research Interest

URL

Physicians for Human Rights

100 Boylston Street, Suite 702

Boston, MA 02116, USA

Phone: (617) 695-0041; Fax: (617) 695-0307

NGO

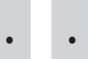

http://www.pgs.ca/pages/

Idmn0.html

Prosthetics Outreach Foundation

726 Broadway, Suite 306

Seattle, Washington 98122, USA

Phone: (206) 726-1636; Fax: (206) 726-1637

NGO

$\cdot$

Radda Barnen

S-107 88 Stockholm, Sweden

Phone: +46-8-698-9083; Fax: +46-8-698-9012

NGO

\section{RADDHO}

BP 15246

Faculte de Lettres, UCAD

Dakar, Senegal

Phone: + 221246 052; Fax + 221246056

\section{REM}

2. Rue Mouloud Zadi

16000 Algiers Centre, Algeria

Phone: +2132744 101; Fax +2132744 101

NGO

Save the Children - USA Headquarters

54 Wilton Road

Westport, CT 06881, USA

Phone:(203) 221-4045; Fax: (203) 221-4082

Shadow Robot Project

251 Liverpool Road

London N1 1PX, UK

Phone: +44 (0)171 7002487

NGO

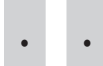

http://www.phrusa.org/

http://www.cyberspace.com/ pof/

http://www.rb.se

http://pprz02.hrzuni-marburg.de/ Haenel/remed/

http://www.savethechildren.org/

http://www.shadow.org.uk 


\section{Organizartion}

South African Campaign to Ban Landmines

POBox 32882

Braamfontein 2017, South Africa

Phone: +27-11-40 34 204; Fax: +27-11-40 31005

P R

\section{SRF Humanity Dog}

Sandsborgsvägen 50

S-122 88 Enskede, Sweden

Phone: +46-8-39 90 00; Fax: +46-8-39 9439

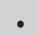

Stiftung Menschen Gegen Minen - MGM

Diessemer Bruch 150

47805 Krefeld, Germany

Phone: 49 (0)2151 555755; Fax: 49 (0) 2151511448

NGO

Stiftung Sankt Barbara

Barbarahof, Kreutzen 17

D-29633 Munster, Germany

Phone:(49) 5055 8900; Fax :(49) 50555053

Swedish Institute of Computer Science

Box 1263

S-164 28 Kista, Sweden

Phone: +46 8752 15 00: Fax: +46 87517230

NGO

Taipei Overseas Peace Service

8th Hoor 102

Kuang Fu S. Road

Taipei, ROC Taiwan

Phone: +886-2-721-02814; Fax: +886-2-776-4360

Thai Campaign

JRS-AP

24 Soi Aree 4

Phaholyothin 7, Phayathai, Bangkok 10400, Thailand

NGO

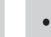

http://www.humanitydog.se/

UK Working Group on Landmines

7 Beechwood Way

Aston Cinton, Bucks HP22 5JW, UK

Phone: +44-1-296-630-596

NGO http://www.mgm.org/

http://muw.dsk.de/rds/20013.htm

http://www.sics.se/

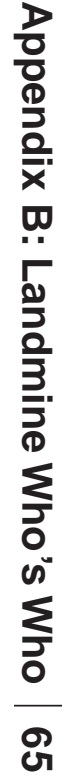


Organization

Union Inter-Africaine de Droits de l'Homme (UIDH)

Type

D

H

esearch Interest

URL

01 BP 1346

Quagadougou 01, Burkina Faso

Phone: +226 316 144; Fax +226 316145

NGO

United Church of Christ Gobal Ministries

475 Riverside Drive

New York, New York 10115, USA

Phone: (212) 870-2838

NGO

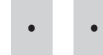

http://www.ucc.org/global/ landmine.htm

\section{Vietnam Veterans of America Foundation}

2001 S Street, NW, Suite 740

Washington, DC20009, USA

Phone: (202) 483-9222; Fax: (202) 483-9312

NGO

War Child

122 East 57th Street

New York, NY 10022 , USA

Phone: (212) 755-5700; Fax : (212) 755-5991

NGO

Youth Approach For Development \& Co-operation (YADC)

GPOBox-3772

Dhaka-1000, Bangladesh

Phone: +88-02-9555321

NGO

Zambia Campaign Ban Landmines

c/o UNZA Medical Library

POBox 50110

Lusaka Zambia

Phone: 2601250 801; Fax 2601253 952/250 753

NGO http://www.vvaf.org

http://www.warchild.org/ 
Appendix C: Bibliography 67

Appendix C

Bibliography 


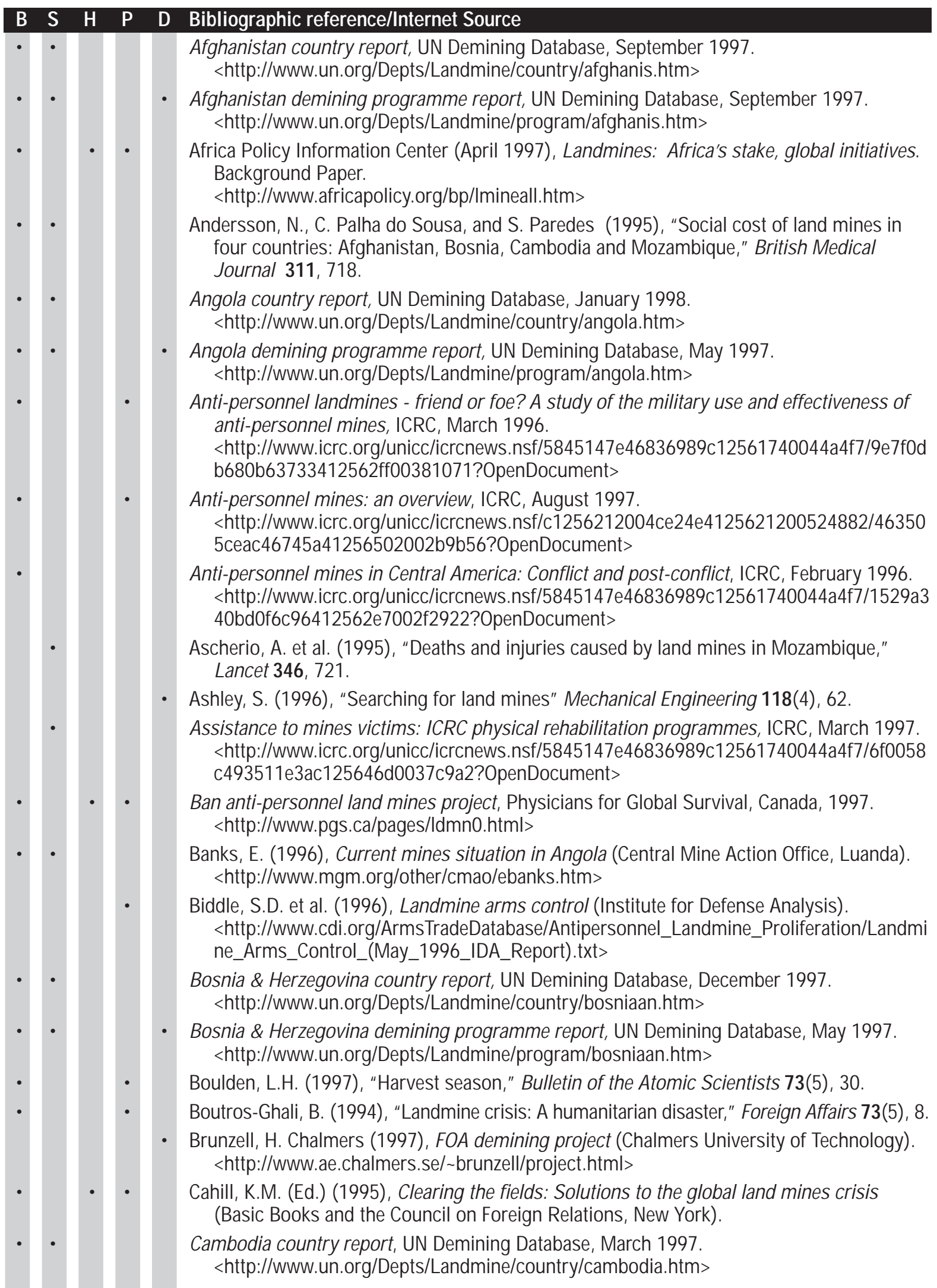




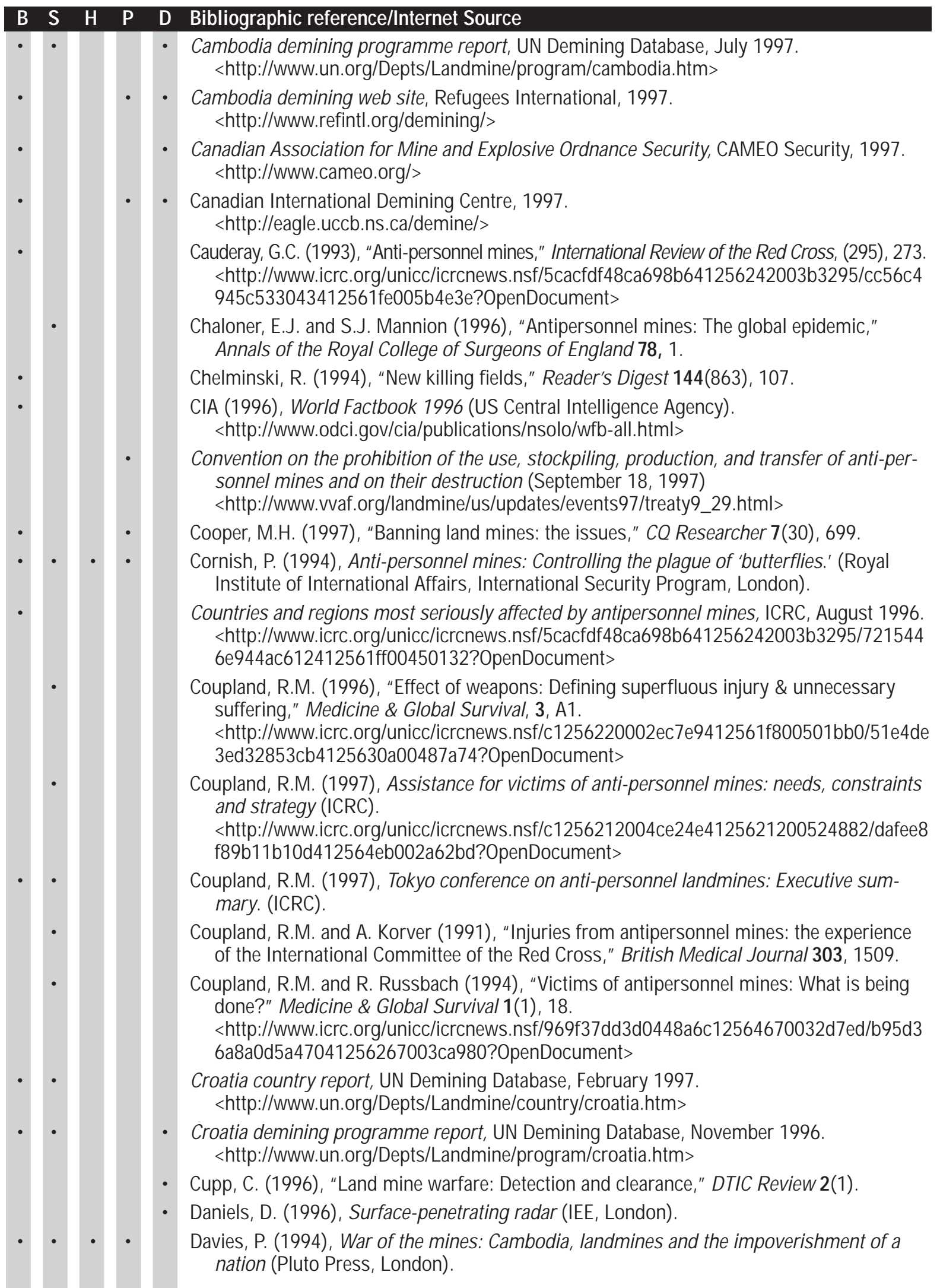




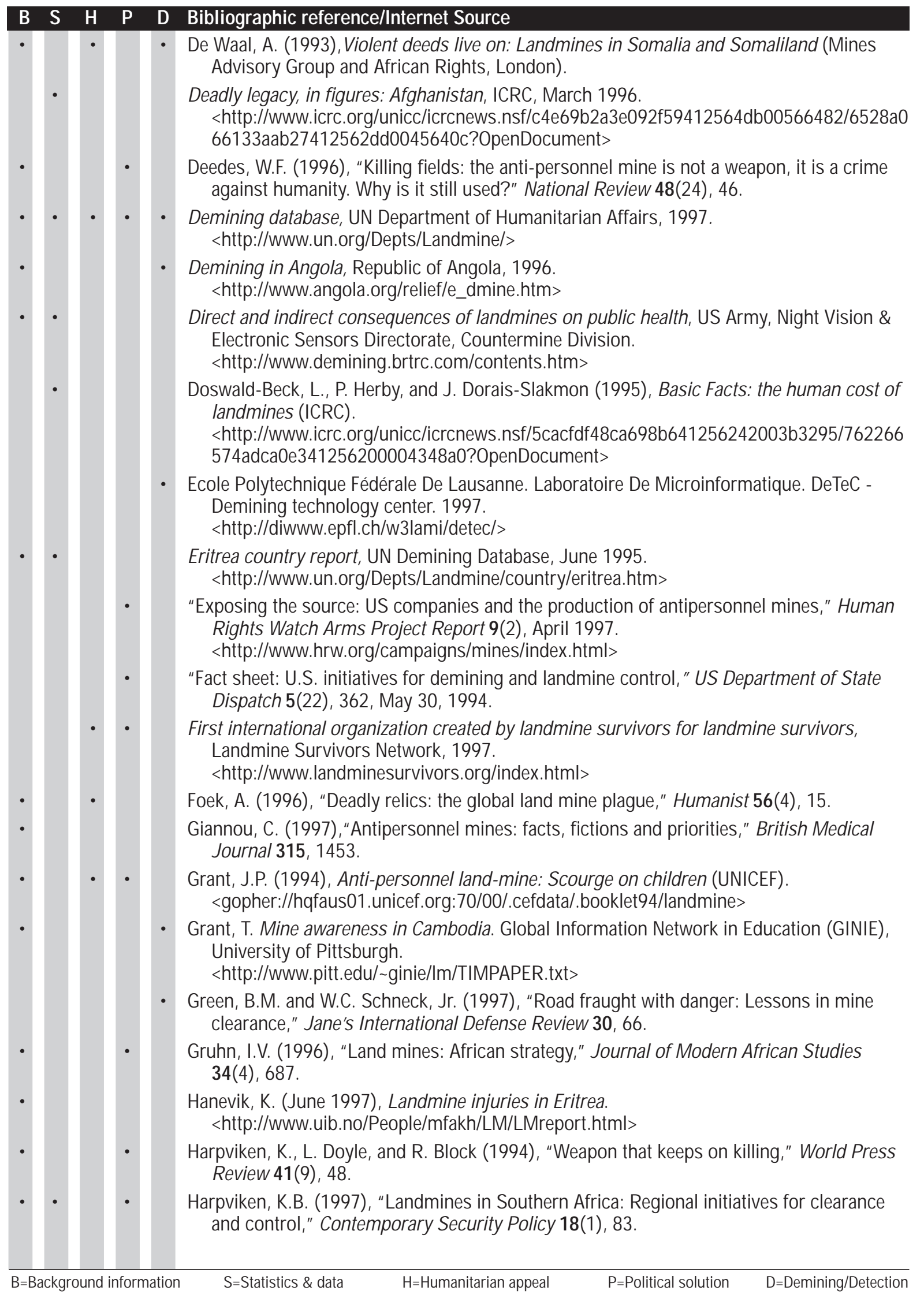




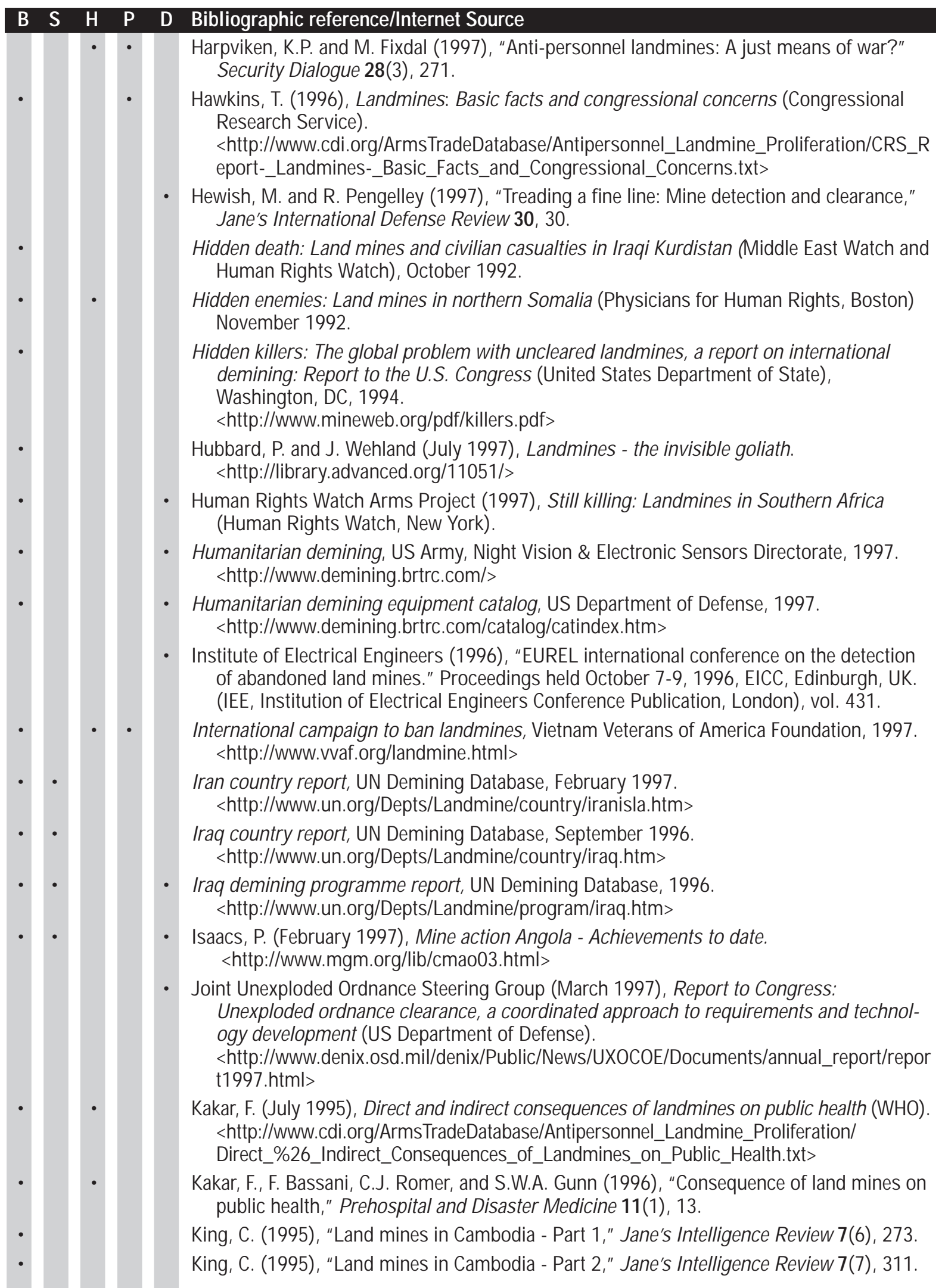

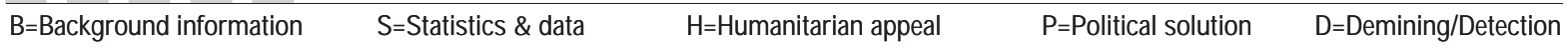




\section{Landmine Policy in the Near-Term}

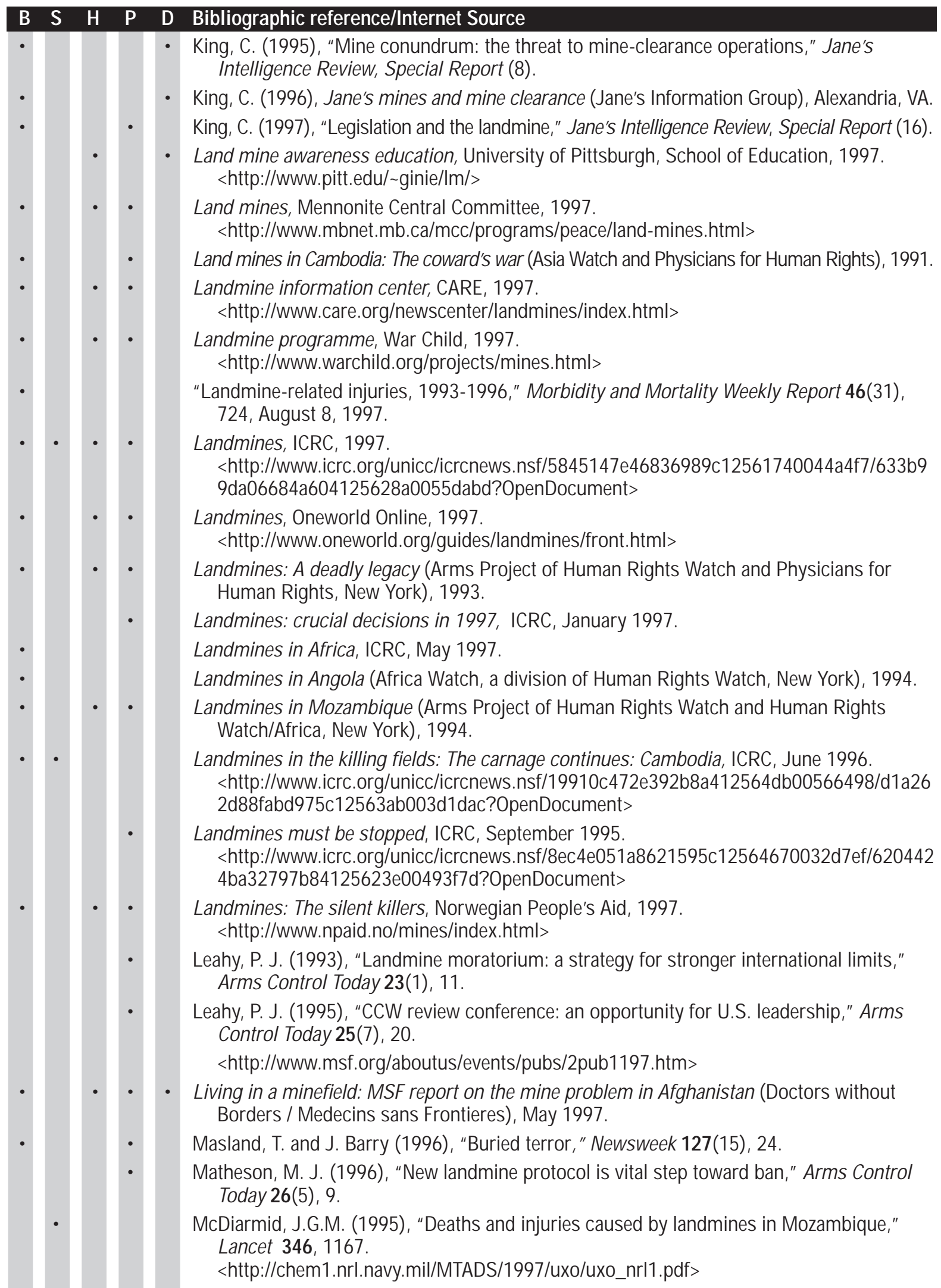




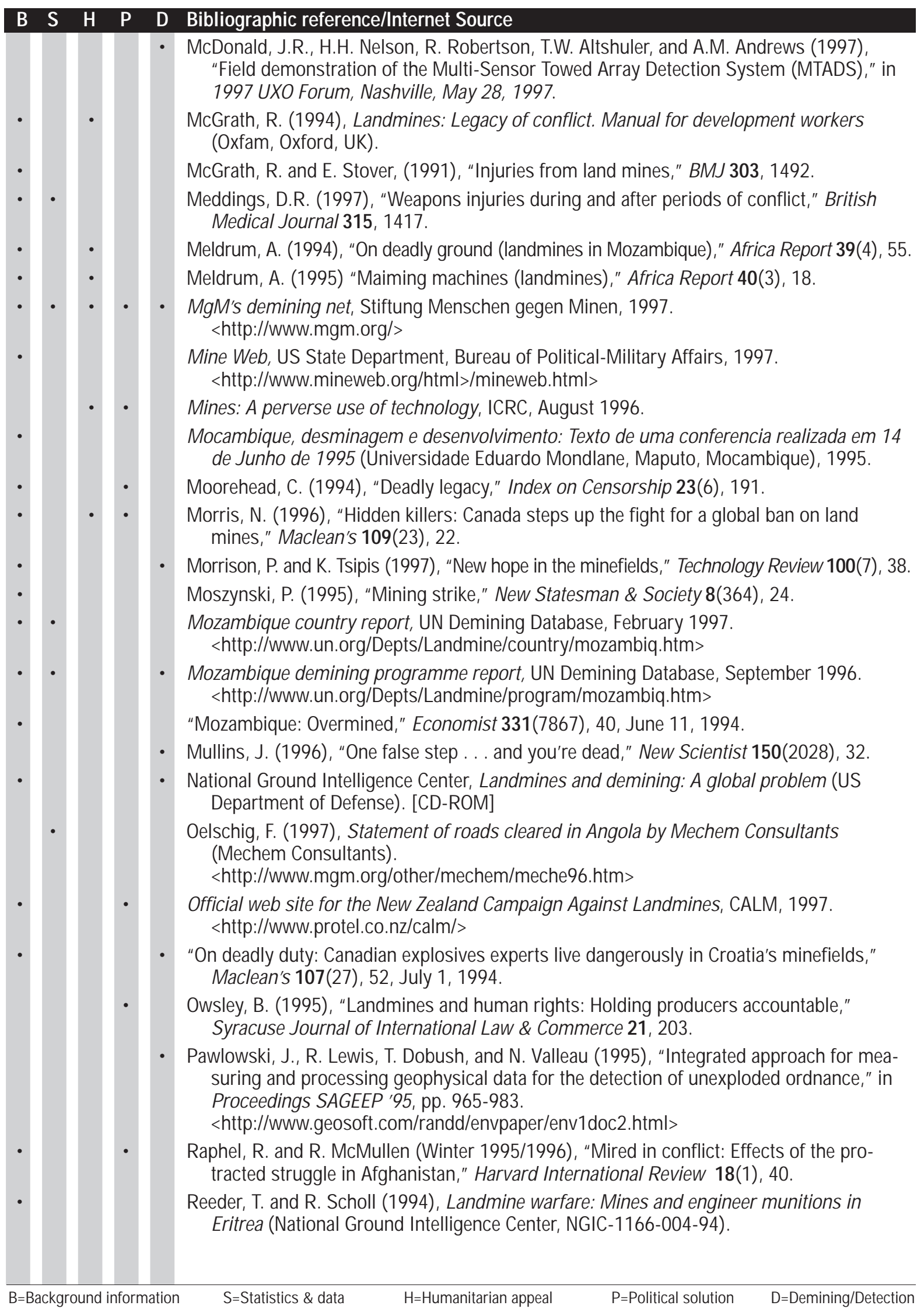




\title{
74 Landmine Policy in the Near-Term
}

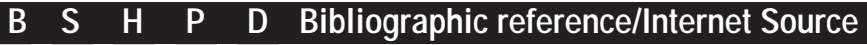 \\ Reeder, T. and C. Taylor (1996), Landmine warfare: Mines and engineer munitions in \\ Central America. (National Ground Intelligence Center, NGIC-1166-005-97). \\ Roberts, S., and J. Williams (1995), After the guns fall silent: The enduring legacy of land- \\ mines (Vietnam Veterans of America Foundation, Washington, DC). \\ - Rouhi, AM. (1997), "Land mines: Horrors begging for solutions," Chemical \& Engineering \\ News 75, 14. \\ Ryle, J. (1993), "Invisible enemy," New Yorker 69(40), 120. \\ Safe lane, Canada Department of Foreign Affairs and International Trade, October 1997. \\ $<$ http://www.mines.gc.cal> \\ Scourge of mines in forgotten wars: Southern Caucasus, ICRC, March 1996 \\ <http://www.icrc.org/unicc/icrcnews.nsf/5cacfdf48ca698b641256242003b3295/aa57cb \\ 7696c25e9041256325004f6e8f?OpenDocument> \\ Silent menace: Landmines in Bosnia and Herzegovina, ICRC, December 1997 \\ <http://www.icrc.org/unicc/icrcnews.nsf/5845147e46836989c12561740044a4f7/00f22d \\ ed76c5ad8c4125656b00454309?OpenDocument>
}

- Society of Photo-Optical Instrumentation Engineers (1995), "Detection technologies for mines and minelike targets," Proceedings, Orlando, R, April 17-21, 1995 (SPIE, Bellingham, WA), vol. 2496.

- Society of Photo-Optical Instrumentation Engineers (1996), "Detection and remediation technologies for mines and minelike targets," Proceedings, Orlando, R, April 9-12, 1996 (SPIE, Bellingham, WA), vol. 2765

- Society of Photo-Optical Instrumentation Engineers (1997), "Detection and remediation technologies for mines and minelike targets 2," Proceedings, Orlando, R, April 21-24, 1997 (SPIE, Bellingham, WA), vol. 3079.

Somalia country report, UN Demining Database, August 1996. $<$ http://www.un.org/Depts/Landmine/country/somalia.htm>

- Somalia demining programme report, UN Demining Database, November 1996. $<$ http://www.un.org/Depts/Landmine/program/somalia.htm>

Somerville, K. (1995), "Angola: Reaping a deadly harvest," World Today 51(8-9), 157.

Sommaruga, C. (1996), Landmines: from global negotiations to national and regional initiatives (ICRC).

<http://www.icrc.org/unicc/icrcnews.nsf/5cacfdf48ca698b641256242003b3295/21b1d1 e073b56eb5c125637d004ac388?OpenDocument>

SPCinformation services: Land mine/ordnance detection references, System Planning Corporation, 1996. $<$ <ttp://www.sysplan.com/Info/LandMine/index.html>

Spillmann, M. (1997), "Unresolved problem of land mines," Swiss Review of World Affairs, 6. (See map on p. 5, also).

- Stewart, K., Animals and demining, January 1998. <http://fn2.freenet.edmonton.ab.ca/ puppydog/demining.htm>

Stover, E and D. Charles (1991), "Killing minefields of Cambodia," New Scientist 132(1791), 26.

Stover, E et al. (1994), "The medical and social consequences of land mines in Cambodia," JAMA272(5).

Strada, G (1996), "Horror of land mines," Scientific American 274(5), 40.

Taylor, C. and T. Reeder (1994), Landmine assessment survey: Mozambique/Malawi (National Ground Intelligence Center, DST-1160R-010-94-SUP 1).

Taylor, C., T. Reeder, and R. Scholl, R. (1994), Landmine warfare: Mines and engineer munitions in Mozambique (National Ground Intelligence Center, AST-1160H-100-94). 


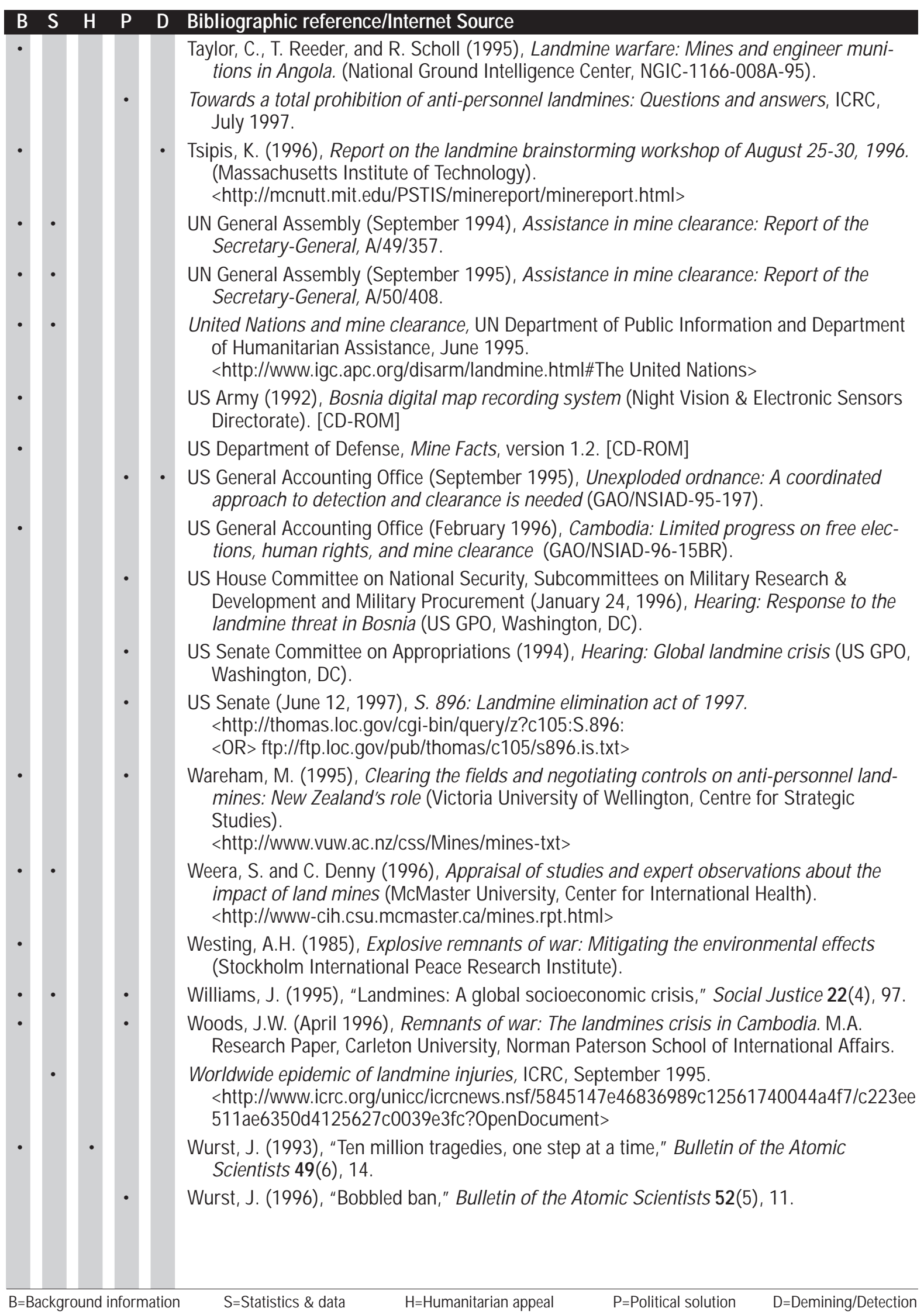




